$10 / 0^{-8.918} 80$

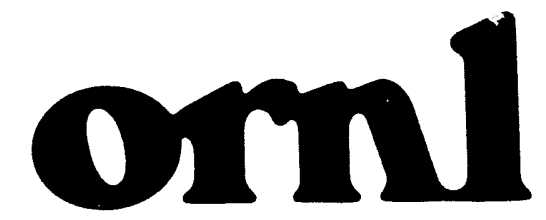

ORNL/Sub/86-57432/1

\section{OAK RIDGE NATIONAL LABORATORY}

wastrav makistra

\section{Development of a Complex Compound Chill Storage System}

Uwe Rockenfeller

Lance Kirol
MANAGED BY

MARTIN MARIETTA ENERGY SYSTEMS, INC.

FAR THE UYITER STATES

DEPARTMENT OF ENERGY 
This report has been reproduced directly from the best available copy.

Available to DOE and DOE contractors from the Office of Scientific and Technical Information, P.O. Box 62, Oak Ridge, TN 37831; prices available from (615) 576-8401, FTS 626-8401.

Available to the public from the National Technical Information Service, U.S. Department of Commerce, 5285 Port Royal Rd., Springfield, VA 22161.

This report was prepared as an account of work sponsored by an agency of the United States Government. Neither the United States Government nor any agency thereof, nor any of their employees, makes any warranty, express or implied, or assumes any legal liability or responsibility for the accuracy, completeness, or usefulness of any information, apparatus, product, or process disclosed, or represents that its use would not infringe privately owned rights. Reference herein to any specific commercial product, process, or service by trade name, trademark, manufacturer, or otherwise, does not necessarily constitute or imply its endorsement, recommendation, or favoring by the United States Government or any agency thereof. The views and opinions of authors expressed herein do not necessarily state or reflect those of the United States Government or any agency thereof. 
ORNL/Sub--86-57432/1

DE92 000410

\title{
DEVELOPMENT OF A COMPLEX COMPOUND CHILL STORAGE SYSTEM
}

\author{
Uwe Rockenfeller \\ Lance Kirol
}

Date Published - August 1991

\author{
Prepared by \\ Rocky Research \\ 1598 Foothill Drive \\ Boulder City, NV 89005 \\ under Subcontract No. 86X-57432V \\ OAK RIDGE NATIONAL LABORATORY \\ Oak Ridge, Tennessee 37831-6285 \\ managed by \\ MARTIN MARIETTA ENERGY SYSTEMS, INC. \\ for the \\ U.S. DEPARTMENT OF ENERGY \\ under contract DE-AC05-84OR21400
}


LIST OF FIGURES $\ldots \ldots \ldots \ldots \ldots \ldots \ldots \ldots \ldots \ldots \ldots \ldots, \mathbf{v}$

LIST OF TABLES $\ldots \ldots \ldots \ldots \ldots \ldots \ldots \ldots \ldots \ldots \ldots \ldots \ldots \ldots \ldots \ldots$

ACKNOWLEDGEMENTS $\ldots \ldots \ldots \ldots \ldots \ldots \ldots \ldots \ldots \ldots \ldots$ viii

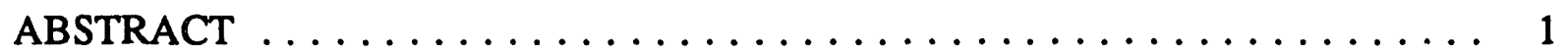

1. INTRODUCTION $\ldots \ldots \ldots \ldots \ldots \ldots \ldots \ldots \ldots \ldots \ldots \ldots \ldots \ldots \ldots$

2. COMPLEX COMPOUND THERMAL STORAGE SYSTEM CONCEPTS $\ldots \ldots 4$

3. SYSTEM DEVELOPMENT $\ldots \ldots \ldots \ldots \ldots \ldots \ldots \ldots \ldots \ldots, 8$

3.1 EQUILIBRIUM PROPERTIES $\ldots \ldots \ldots \ldots \ldots \ldots \ldots \ldots \ldots$

3.2 REACTIVITY ANALYSIS $\ldots \ldots \ldots \ldots \ldots \ldots \ldots \ldots \ldots \ldots$

Complex Compound Slurry System .............. 13

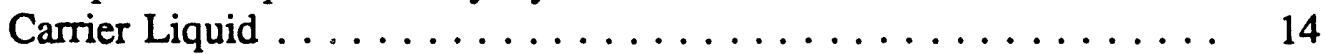

Optimized Solid-Bed Reactors $\ldots \ldots \ldots \ldots \ldots \ldots \ldots \ldots .20$

3.3 OPTIMIZATION OF SOLID-BED REACTORS FOR TES ...... 24

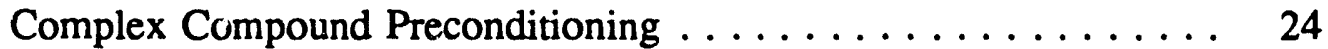

Heat Exchanger Loading Density ................ 24

Heat Rejection Temperature and Approach Temperature ...... 27

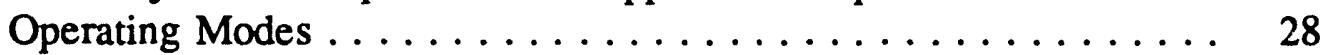

3.4 BENCH-SCALE DEMONSTRATION $\ldots \ldots \ldots \ldots \ldots \ldots \ldots, 30$

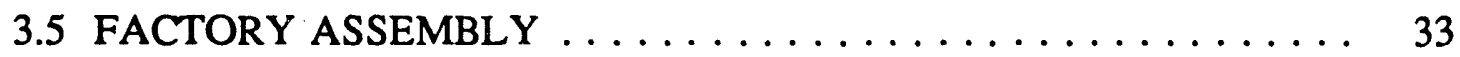

Reactor Design and Construction $\ldots \ldots \ldots \ldots \ldots \ldots \ldots . \ldots \ldots$

Testing and Performance $\ldots \ldots \ldots \ldots \ldots \ldots \ldots \ldots \ldots \ldots \ldots$

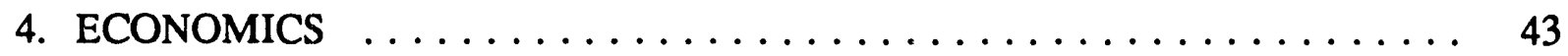

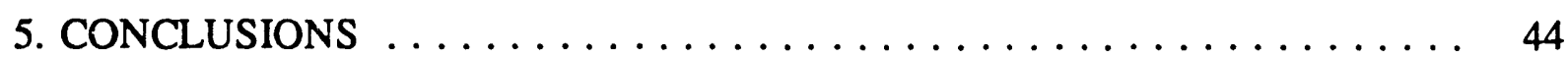

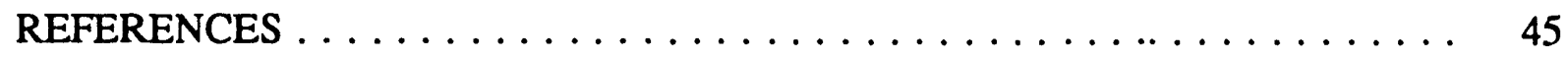

APPENDIX: BACKGROUND OF COMPLEX COMPOUND CHEMISTRY $\ldots 46$

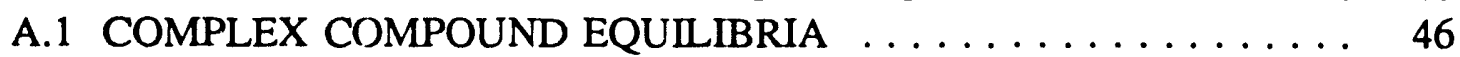

A.2 HEAT AND MASS TRANSFER IN COMPLEX COMPOUNDS $\ldots \quad 50$

REFERENCES $\ldots \ldots \ldots \ldots \ldots \ldots \ldots \ldots \ldots \ldots \ldots \ldots \ldots \ldots \ldots \ldots \ldots$ 


\section{LIST OF FIGURES}

\section{Figure}

Page

1 Cool storage concept using compressor. $\ldots \ldots \ldots \ldots \ldots \ldots \ldots$

2 Charge and discharge of complex compound chill storage system. . . . . . 6

3 Refrigeration loop with complex compound TES system. . . . . . . . 6

4 Vapor pressure-temperature relation for $\mathrm{CC} 480-1110 . \ldots \ldots \ldots \ldots$

5 Vapor pressure-temperature relation for $\mathrm{CC180-1580} \ldots \ldots \ldots \ldots$

6 Tension curve for $\mathrm{CC} 480-1110$ at $18^{\circ} \mathrm{C} \ldots \ldots \ldots \ldots$

7 Tension curve for $\mathrm{CC} 180-1580$ at $66^{\circ} \mathrm{C} . \ldots \ldots \ldots \ldots$

8 Adsorption rates of CC180-1580 during cyclic operation. . . . . . . . 12

9 Desorption rates of CC180-1580 during cyclic operation. . . . . . . 12

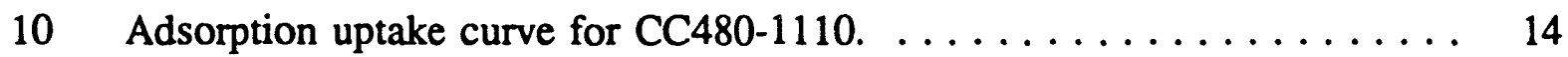

11 Schematic of carrier liquid-complex compound solubility test system. . . . 16

12 Carrier liquid proof-of-feasibility apparatus. . . . . . . . . . . . 19

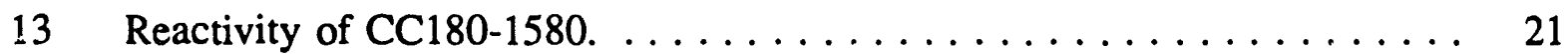

14 Reaction rates and coordination sphere utilization with various complex compound conditioning. Data are for CC180-1580 adsorptions at $45^{\circ} \mathrm{C}$ and

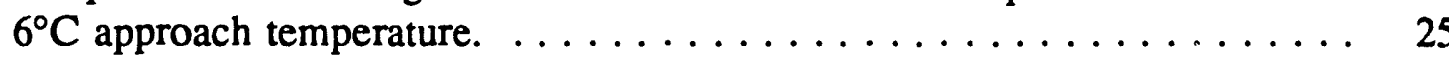

15 Usable mole number change for $\mathrm{CC} 180-1580$ with $6^{\circ} \mathrm{C}$ approach

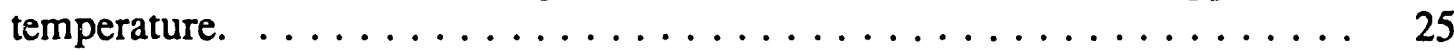

16 Cost of reactor internals and vessels for thermal storage using CC180-

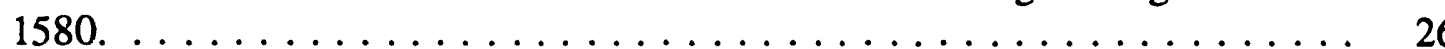

17 Coordination sphere utilization as a function of approach temperature for $\mathrm{CC} 180-1580$ at $35^{\circ} \mathrm{C}$ heat rejection. 
18 Coordination sphere utilization as a function of heat rejection temperature for CC180-1580 at an approach temperature of $16^{\circ} \mathrm{C} . \ldots \ldots 28$

19 Comparison of constant rate and constant pressure adsorptions of CC1801580 at $45^{\circ} \mathrm{C}$. Maximum approach temperature is $6^{\circ} \mathrm{C} \ldots \ldots \ldots 29$

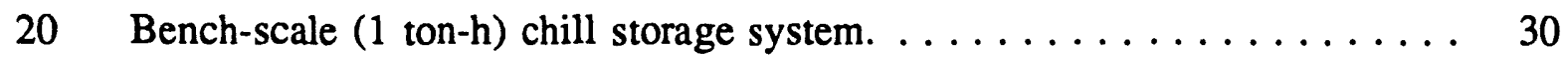

21 Desorptions at $35^{\circ} \mathrm{C}$ in laboratory scale $(0.002$ ton-h) and bench scale (1

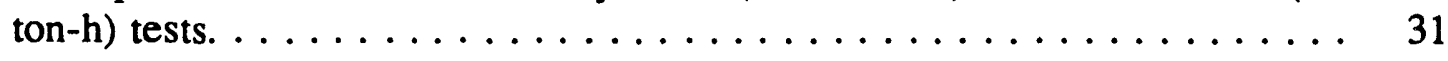

22 Desorptions at $35^{\circ} \mathrm{C}$ in laboratory scale $(0.002$ ton-h) and bench scale (1 ton-h) tests. . . . . . . . . . . . . . . . . . . 32

23 Chill-storage reactor prior to insulation. . . . . . . . . . . . 34

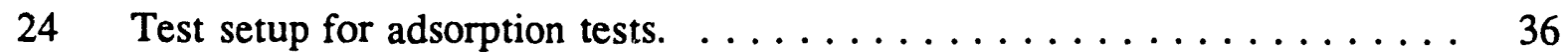

25 Inlet and outlet temperatures of cooling water during second adsorption. Cooling water flow is 40 GPM. . . . . . . . . . . . . 37

26 Reaction rates during the first adsorption at chill storage conditions. ...................... 37

27 Ammonia uptake during first adsorption at chill-storage conditions. ............................ 38

28 Inler and outlet temperatures of water during the first desorption. ....................... 40

29 Approach temperature during desorption. . . . . . . . . . . . . 40

30 Reaction rates during the first desorption. . . . . . . . . . . . 41

A.1 Phase diagram for $\mathrm{BaCl}_{2} \bullet \mathrm{O} / 8 \mathrm{NH}_{3} . \ldots \ldots \ldots \ldots \ldots$ 


\section{LIST OF TABLES}

Table

Page

1 Solubilities of CC480-1110 forming salt in organic liquids. . . . . . . 17

2 Coordination sphere utilization at various TES conditions $\ldots \ldots \ldots 32$

3 Summary specifications of instrumentation used in sorber testing. . . . . . 35 
viii

\section{ACKNOWLEDGEMENTS}

The U.S. Department of Energy (DOE), Office of Utility Technology, sponsored this work as a part of the Thermal Energy Storage Program of Oak Ridge National Laboratory. The developmental work including bench-scale tests was sponsored solely by DOE. The factory assembly work was accomplished with substantial cost sharing by Standard Refrigeration Company of Melrose Park, Illinois. Standard Refrigeration bore all expenses involved with the manufacture and testing of the 4 ton-h reactor vessel described in this report. 


\title{
DEVELOPMENT OF A COMPLEX COMPOUND CHILL STORAGE SYSTEM*
}

\author{
Lance Kirol and Dr. Uwe Rockenfeller
}

\begin{abstract}
A thermal energy storage system applicable to industrial refrigeration needs at temperatures as low as $-28^{\circ} \mathrm{C}$ has been developed. The system is based on the chemical bonding between a gaseous refrigerant and a solid salt. The system has been tested successfully in the laboratory and a small unit capable of holding 4 ton-h has been constructed in a factory environment. Much of the development efforts have centered on designing the reactor/heat exchanger where the salt and the refrigerant are combined. Economic evaluations have been made and show an estimated simple rate of return between 30 and $50 \%$.
\end{abstract}

\section{INTRODUCTION}

Thermal (chill) storage has long been recognized as an economically viable method of peak loid shifting and shaving. The economics are driven primarily by utility programs that offer installment incentives, off-peak power rates, operating hours with no demand charge, and added refrigeration capacity. The major drawbacks of thermal storage are an uncertain future for utility incentive programs and increased electric power consumption because of thermodynamic heat transfer losses inherent to thermal storage equipment.

Thermal storage systems developed and marketed in the past enjoy their most significant market penetration in commercial air conditioning. Most systems offered today provide a 20 to $50 \%$ return on investment in utility areas with active incentive programs for commercial installations.

"Units used throughout this report are common to and exclusive in the industry. 
Today's commercially available thermal storage products are based on phase change materials or sensible heat systems operating at or above $0^{\circ} \mathrm{C}$. Therefore, they are almost exclusively applicable to commercial and industrial air conditioning. The refrigeration industry of the United States, which operates refrigeration equipment at evaporator temperatures between $-45^{\circ} \mathrm{C}$ and $-7^{\circ} \mathrm{C}$, has not been successfully approached with thermal storage products. Low temperature brine and salt augmented ice storage systems do not provide satisfactory operating characteristics or economics. In particular, successful thermal storage systems operating below $-7^{\circ} \mathrm{C}$ have not been developed.

The refrigeration industry, however, is an attractive target for thermal storage because such plants operate typically $365 \mathrm{~d} / \mathrm{yr}$ and are large, typically in the range of 200 to 500 tons refrigeration capacity per installation. Refrigerated warehouses alone account for several hundred thousand tons of refrigeration capacity. The typical operating temperatures, i.e., $-40^{\circ} \mathrm{C}$ for flash freezing, and $-28^{\circ} \mathrm{C}$ and $-7^{\circ} \mathrm{C}$ for product storage, result in much lower refrigeration equipment performances than obtainable in heating, ventilating, and air conditioning (HVAC) applications. This leads to higher electrical power demand.

Development of a low-temperature thermal storage system is geared toward the refrigeration market. To provide a successful product, several requirements must be fulfilled. First, the refrigeration market is not a single-temperature target as encountered in the HVAC industry. As a minimum, three temperature levels $\left(-7^{\circ} \mathrm{C},-28^{\circ} \mathrm{C}\right.$, and $\left.-40^{\circ} \mathrm{C}\right)$ must be addressed. Second, capacity and efficiency of vapor compression equipment are very sensitive to suction pressures at low temperature levels; excessive approach temperatures dictated by specific phase change materials must be avoided. Finally, the technology must be simple enough to allow for easy system integration and minimum maintenance. The return on investment must exceed 25 to $33 \%$ depending on the particular application. ${ }^{1}$ These criteria are not satisfied by today's commercially available technology.

Applying the principle of complexing a metal inorganic salt with ammonia refrigerant provides the necessary operating $t^{-}$. . perature flexibility. A system of this type can be operated at several temperatures in the above range by merely substituting various salts for the adsorbing media. Thus, one hardware design could be used for an entire line of thermal storage products. Ninety percent of U.S. refrigeration warehouses operate with 
ammonia refrigerant, making it possible to design a direct-contact complex compound thermal storage system for this industry.

Complex compound thermal storage systems operate on a chemisorption principle. The principal components of the system are two containers; one contains liquid ammonia with a free surface, and the other contains a salt that can take up ammonia by chemisorption. At the same temperature, the equilibrium vapor pressure of the ammoniated salt with ammonia as the ligand is significantly lower than the saturated vapor pressure of ammonia. The thermal energy storage (TES) system is charged and discharged by transferring ammonia between the two containers and exploiting the heats of vaporization and sorption of ammonia. During the adsorption of ammonia by the salt, heat is released and must be carried from the system; the desorption process is endothermic. This concept is described fully in Sect. 2, with additional detail in the Appendix.

Three potential system designs were analyzed with the product requirements in mind. This analysis is discussed in Sect. 3. The best design proved to be an optimized solid-bed reactor. A recent breakthrough in complex compound packaging and heat exchanger development provided average approach temperatures of $4^{\circ} \mathrm{C}$ to $5^{\circ} \mathrm{C}$. Based on these findings, a solid-vapor reactor was developed and demonstrated to deliver up to 1 ton-h of chill storage at $-28^{\circ} \mathrm{C}$. Initial economic analyses, performed by independent refrigeration engineering specialists, showed projected returns on investment between $\mathbf{3 0}$ and $60 \%$ depending on the utility area (see Sect. 4). A final phase of the project focussed on demonstrating the technical viability of increasing the scale to a single reactor with over 4 ton-h of chill storage, and demonstrating the feasibility of factory assembly of a complex compound reactor.

Development of a complex compound low-temperature TES system is described herein from basic chemical principles through factory assembly and testing. Important application engineering issues and an economic outlook are addressed as well. Future development should focus on optimization of the sorber heat exchanger surface configuration, as is discussed in Sect. 5. 


\section{COMPLEX COMPOUND THERMAL STORAGE SYSTEM CONCEPTS}

Ammoniated, hydrated, alcohol, or ammine complex compounds consisting of a solid metal salt and a gaseous refrigerant ligand are ideal media for heat, cool, and chill storage systems. An appendix is included in this report to provide useful background information about complex compound chemistry and reaction rates. The multitude of salt adsorbents and refrigerant adsorbates makes it possible to cover a temperature range from approximately $-50^{\circ} \mathrm{C}$ to $300^{\circ} \mathrm{C}$. Storage operation is possible by moving refrigerant back and forth either between two different complex compounds or between one complex compound and a refrigerant storage tank. The storage system is "discharged" as the refrigerant is adsorbed by the complex compound, permitting heat absorbed at a low temperature to be released at a high temperature. The system is "charged" as the refrigerant is released by the complex compound and returned to a liquid state. This convention means that the storage system is available to meet a cooling load at the end of a charge cycle.

Systems can be designed as direct refrigerant contact or indirect thermally coupled systems. The direct contact design uses the refrigerant in the vapor compression cycle as the ligand gas in the storage medium. This has the advantage of low heat transfer gradients, but presents oil management issues between the complex compound and the compressor. The most relevant refrigerant ligand for direct contact systems is ammonia since it is commonly used both as a refrigerant in compressor units and as a ligand in complex compound formation. The indirect contact system is coupled to the refrigeration unit and/or a waste heat source through a heat exchanger. This causes an additional temperature gradient, but it yields the safest integration of the storage system with existing chiller or refrigeration units.

Figure 1 shows the schematic of a compressor-actuated direct contact chill storage system. The system operates by moving refrigerant back and forth between one complex compound and a ligand container (i.e., a refrigerant storage tank). Systems using two complex compounds can be developed on the same basis. During discharge, the liquid 


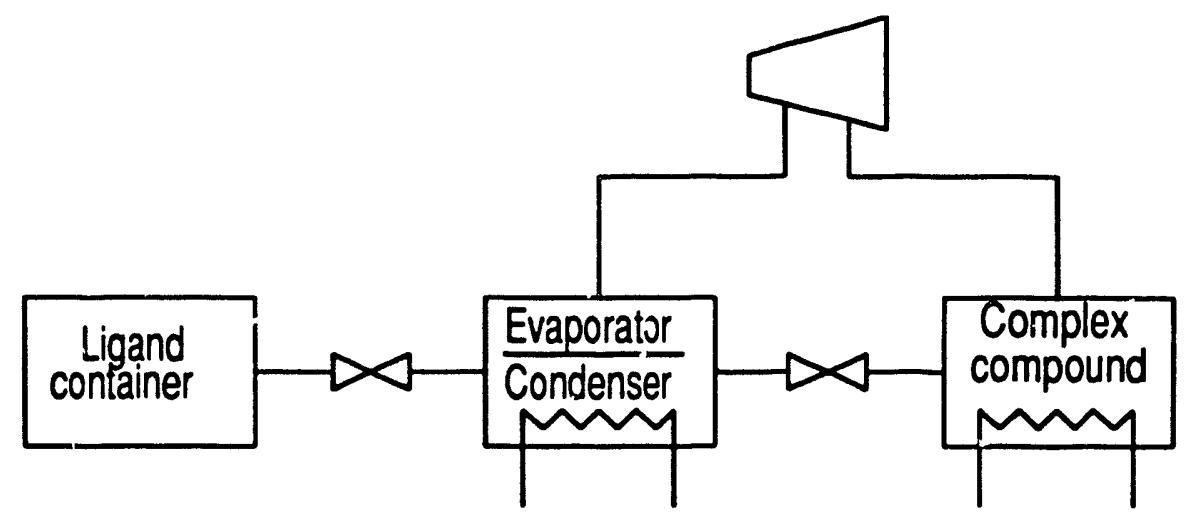

Fig. 1. Cool storage concept using compressor.

ammonia is drawn out of the ligand storage tank into the evaporator. Here the ammonia evaporates, providing chill to the load. The vapor pressure of the ammonia at the low evaporator temperature is higher than the complex compound vapor pressure. The refrigerant therefore flows to the complex compound reactor through the valve shown where it undergoes an exothermic adsorption reaction. The pressure and temperature within the complex compound reactor are maintained by an evaporative condenser or cooling tower. Figure 2 shows the discharge process in the phase diagram for CC180-1580, a typical complex compound.

In order to charge the system, the ammonia gas must be returned to the ligand container. Chill storage systems can be designed to use a heat source/sink to reverse the flow. This can be accomplished by either raising the temperature and pressure of the complex compound sufficiently high or by cooling the condenser sufficiently low to condense the ammonia and ultimately lead the liquid back into the ligand storage tank. However, most envisioned applications use a compressor as shown in Fig. 1 to compress he ligand refrigerant which is in direct contact with the complex. In any case, the pressure gradient must be reversed such that a positive flow of ammonia from the complex to the condenser can be maintained.

A chill storage system directly ccupled to a receiver as shown in Fig. 3 is an attractive concept for development. During the charge process, the compressor removes gas from the complex compound reactor. Condenser heat is used to maintain the complex 


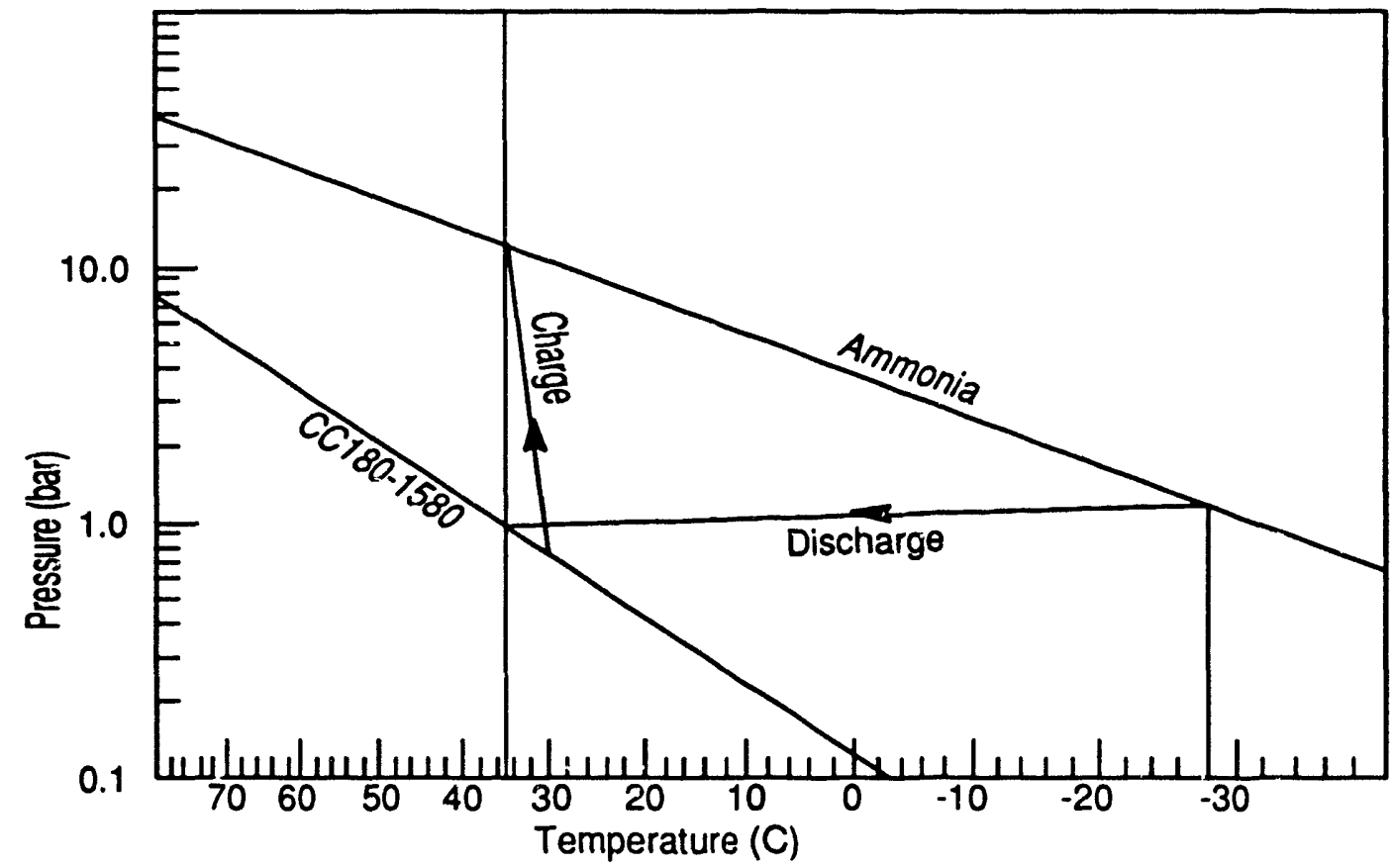

Fig. 2. Charge and discharge of complex compound chill storage system.

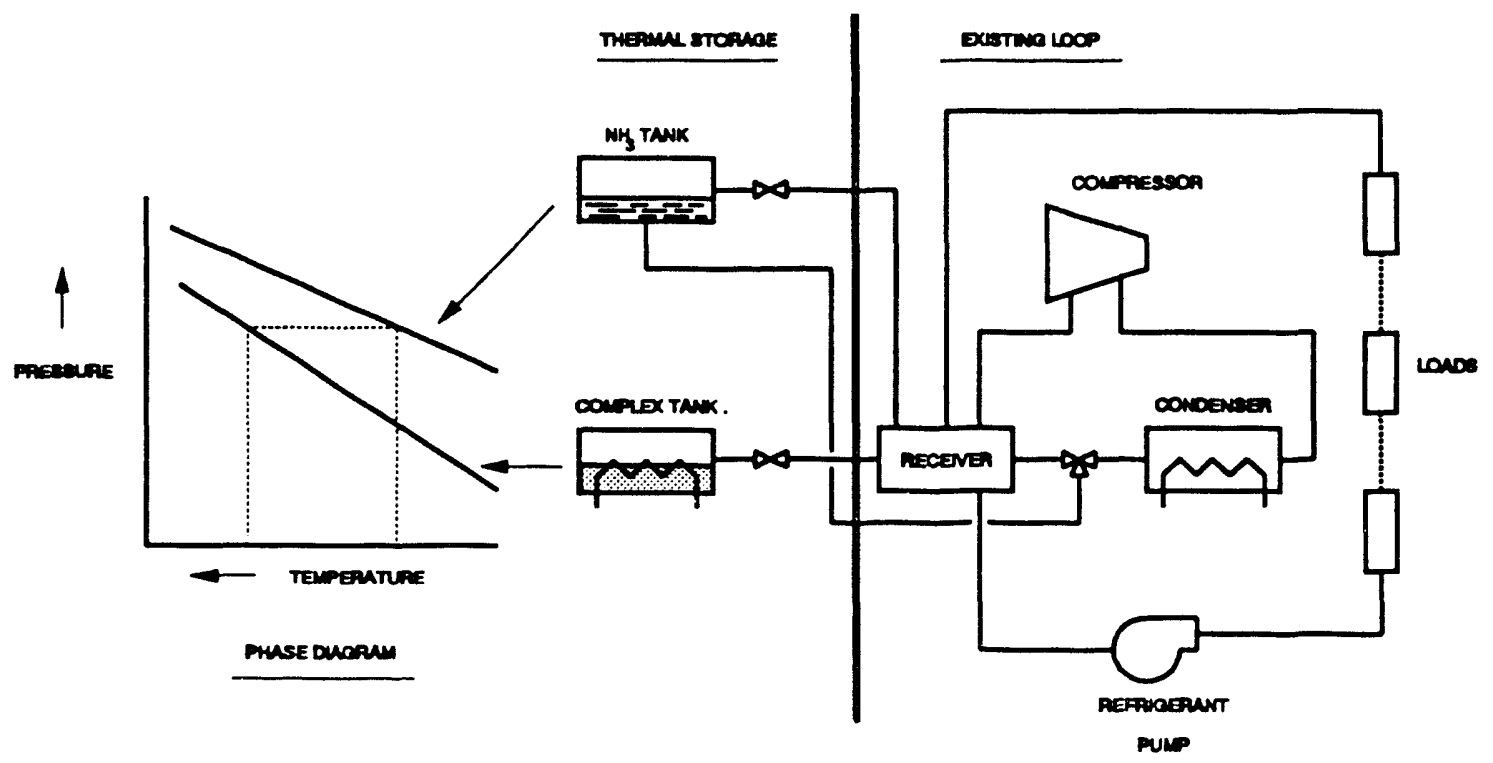

Fig. 3. Refrigeration loop with complex compound TES system. 
compound temperature around $35^{\circ} \mathrm{C}$. During the discharge process, the compressor is not operating and adsorption of ammonia into the complex compound removes heat from the receiver. Refrigeration continues via flow of liquid refrigerant from the ammonia storage tank to the receiver and from there to the load, partial evaporation of refrigerant at the load, and yapor flow to the receiver and into the complex compound. The complex compound temperature is maintained by means of the evaporative condenser or cooling tower. This system can be easily retrofit to an existing pumped recirculation refrigeration system as shown in Fig. 3. 


\section{SYSTEM DEVELOPMENT}

The technical approach toward development of low-temperature chill storage equipment can be divided into several development steps. Initially, complex compounds with suitable vapor pressure equilibria for the thermal storage temperatures of interest were identified. An experimental investigation of media stability and the maximum possible refrigerant density in the complex was then conducted. After completing equilibrium property analyses, the dynamic reactivity properties were investigated as functions of various operating parameters. Once the most appropriate heat and mass transfer method was selected, the development of cost effective hardware and system integration strategies began.

\subsection{EQUILIBRIUM PROPERTIES}

Screening of Rocky Research's complex compound database led to identification of numerous ammoniated complex compounds with vapor pressure equilibria that allow for ammonia adsorption processes at pressures between 0.4 bar and 4 bar (6 psia and 60 psia) resulting in evaporator temperatures between $-40^{\circ} \mathrm{C}$ and $0^{\circ} \mathrm{C}$. Of this group, two complex compounds-CC480-1110 and CC180-1580-showed particular promise because of their capability to provide refrigeration around $-7^{\circ} \mathrm{C}$ and $-28^{\circ} \mathrm{C}$, the most prevalent temperatures in the refrigeration market. The vapor pressure equilibria for these compounds are depicted in Figs. 4 and 5.

Storage density is determined by the mass fraction of the regenerable ammonia refrigerant contained in a unit mass of complex compound. The mass fraction is expressed as a coordination number, corresponding to the number of ligand molecules bound to a central salt molecule. Refrigerant uptake at constant pressure and temperature was measured. Figures 6 and 7 show the tension curves of the two candidate complex compounds. These results indicate that over a large region, the pressure and temperature 


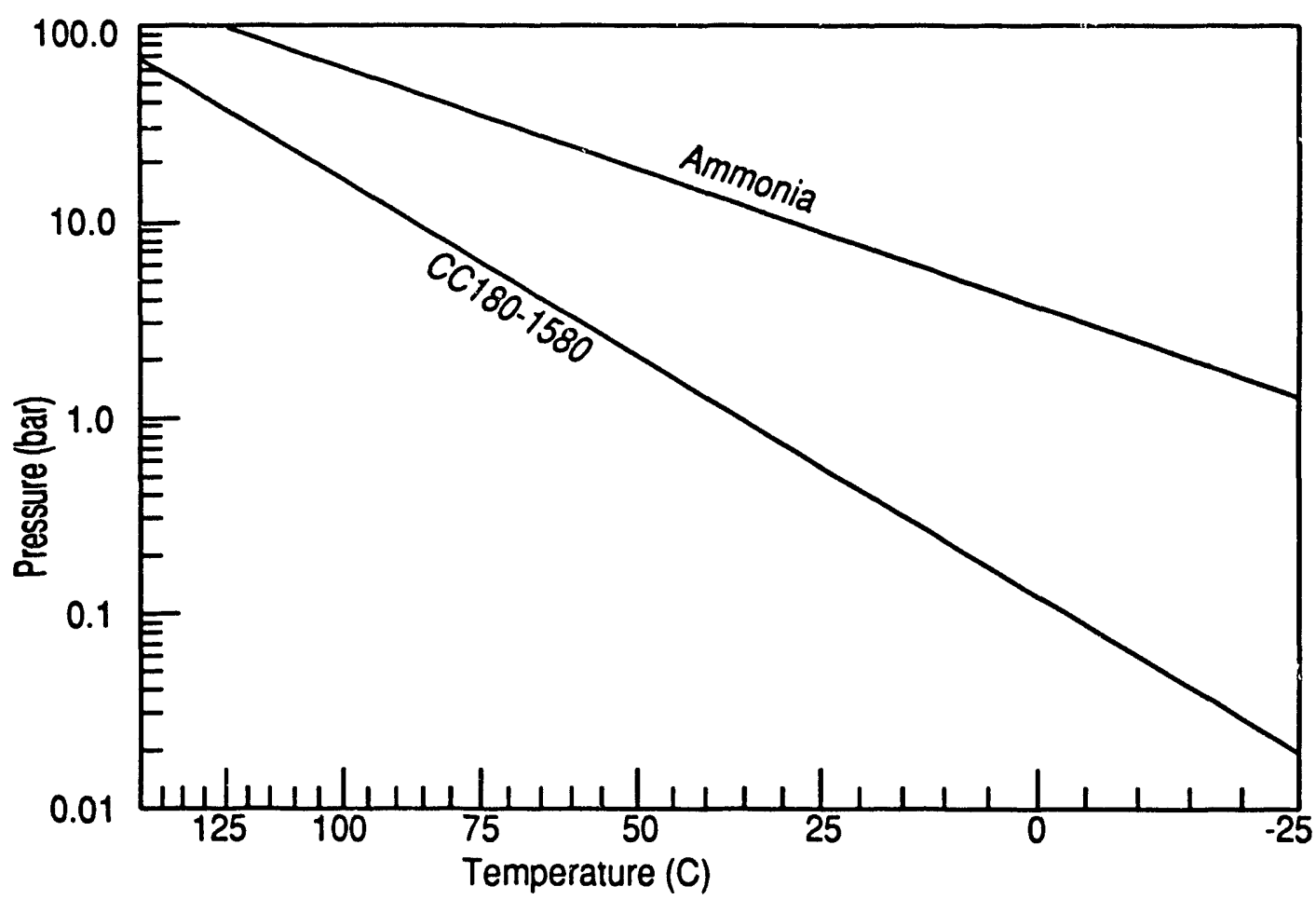

Fig. 4. Vapor pressure-temperature relation for CC480-1110.

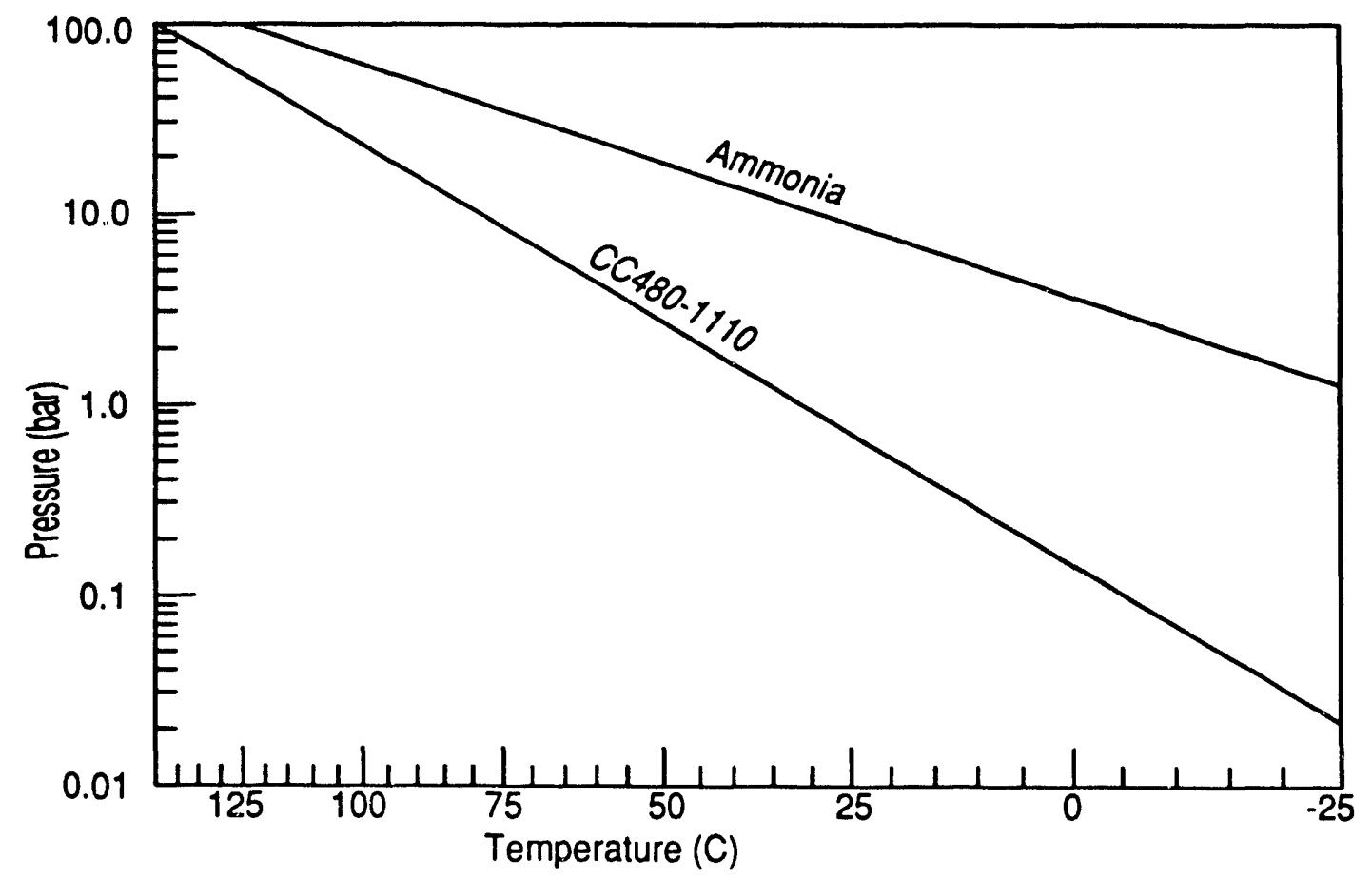

Fig. 5. Vapor pressure-temperature relation for CC180-1580. 


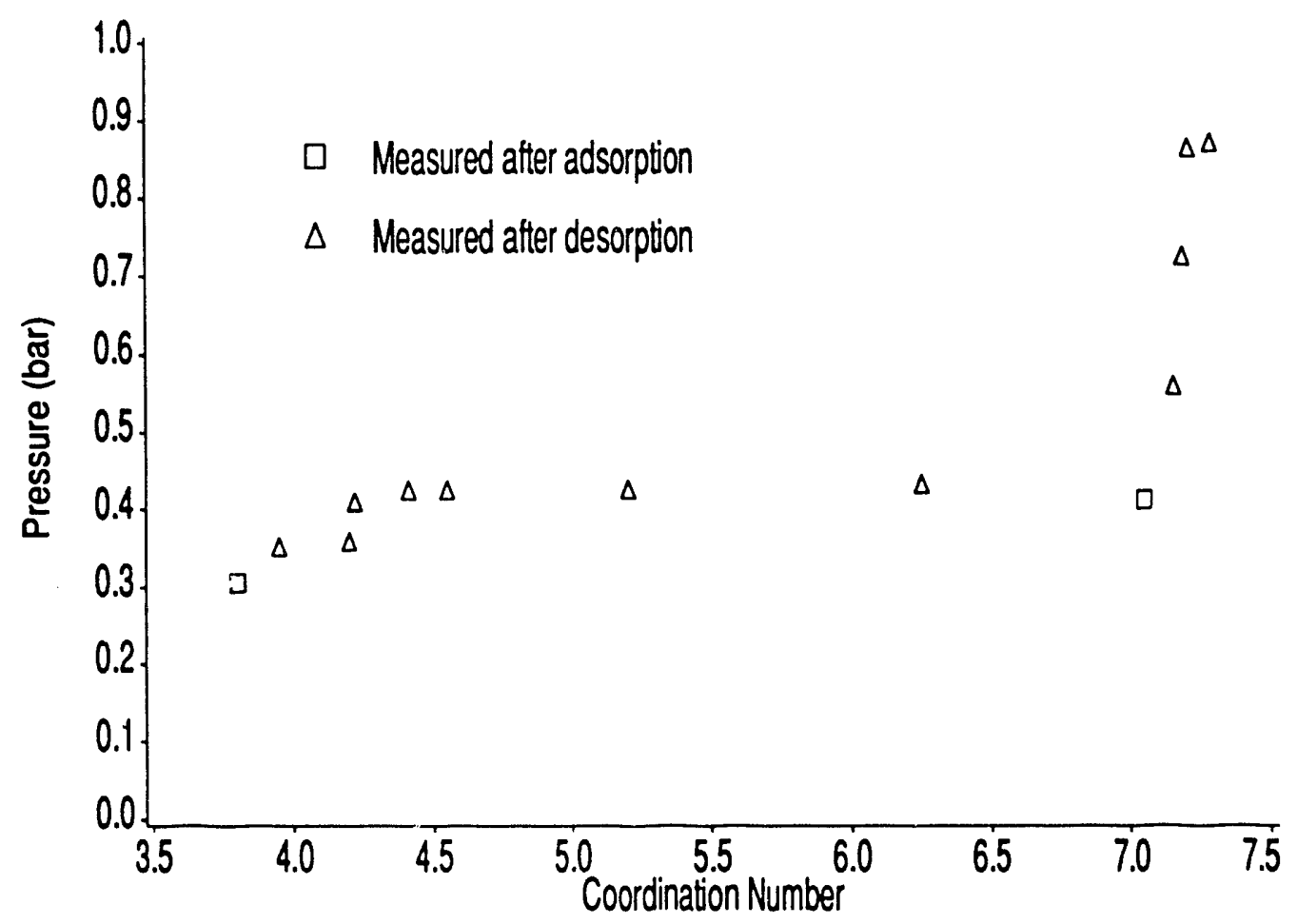

Fig. 6. Tension curve for $\mathrm{CC} 480-1110$ at $18^{\circ} \mathrm{C}$.

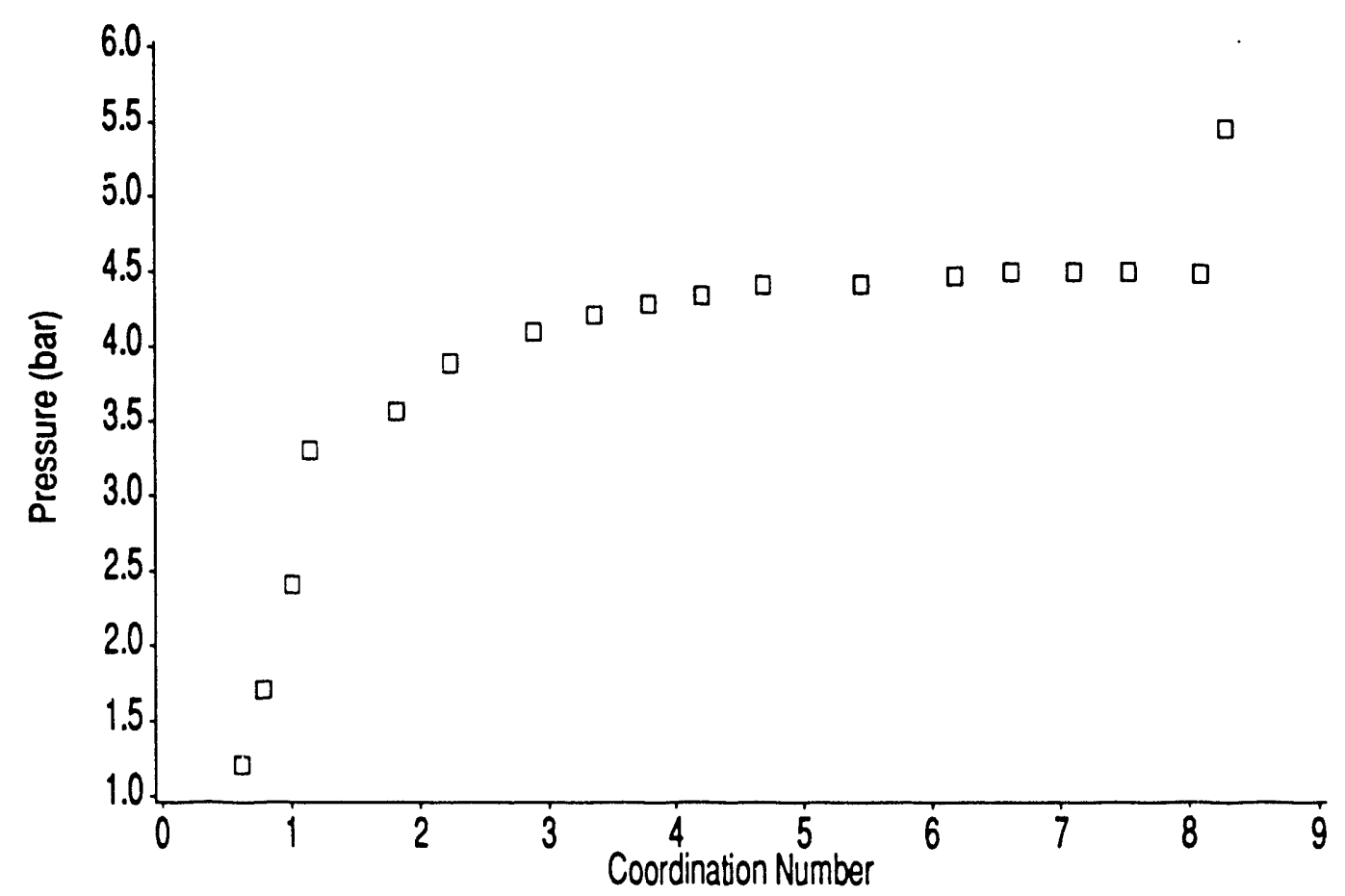

Fig. 7. Tension surve for $\mathrm{CC} 180-1580$ at $66^{\circ} \mathrm{C}$. 
are relatively constant as the coordination number (and therefore stored energy) changes. This behavior is similar to latent heat storage in single component phase change materials.

The long-term ability of complex compounds to adsorb and desorb over many cycles is an important issue for thermal storage systems which must cycle once per day and have a lifetime of many years. Verification of cycle life over thousands of cycles is therefore required. However, it is expected that any changes in reactivity, size of the useful coordination sphere (arrangement of refrigerant molecules bound to a central salt molecule), or vapor pressure would become evident during the first 50 or so cycles, and certainly during the first few hundred cycles. A first estimate of the effects of cycling was obtained by adsorbing and desorbing complex compound CC180-1580 for over 700 cycles. The test was conducted by maintaining an evaporator/condenser at constant temperature, and cycling the temperature of the complex compound so that the complex compound vapor pressure was alternately above and below the evaporator/condenser pressure. Temperature cycling, from 40 to $79^{\circ} \mathrm{C}$, was accomplished by using solenoic valves to connect alternately the reactor heat exchanger to one of two constant temperature bath circulators. The reactor was held at each temperature for approximately 30 minutes. The complex compound was contained in a dry-bed reactor. System control and data collection were computerized.

Reaction raies for randomly selected adsorptions and desorptions are illustrated in Figs. 8 and 9, respectively. The variability in the data is small and there are no trends apparent with respect to cycle number. These results, while not proving cyclic stability for many thousands of cycles or stability of other complex compounds, are encouraging in that no degradation of reaction rate or coordination sphere utilization is occurring. They represent the equivalent of nearly two years of thermal storage operation. If long-term problems were to ensue, it is almost certain that a trend would become manifest during the first 700 cycles. The fact that the temperature extremes of the cycle testing-from 40 to $79^{\circ} \mathrm{C}$-are more severe than encountered in a TES system adds further confidence to the temperature and cycle stability of the compounds. 


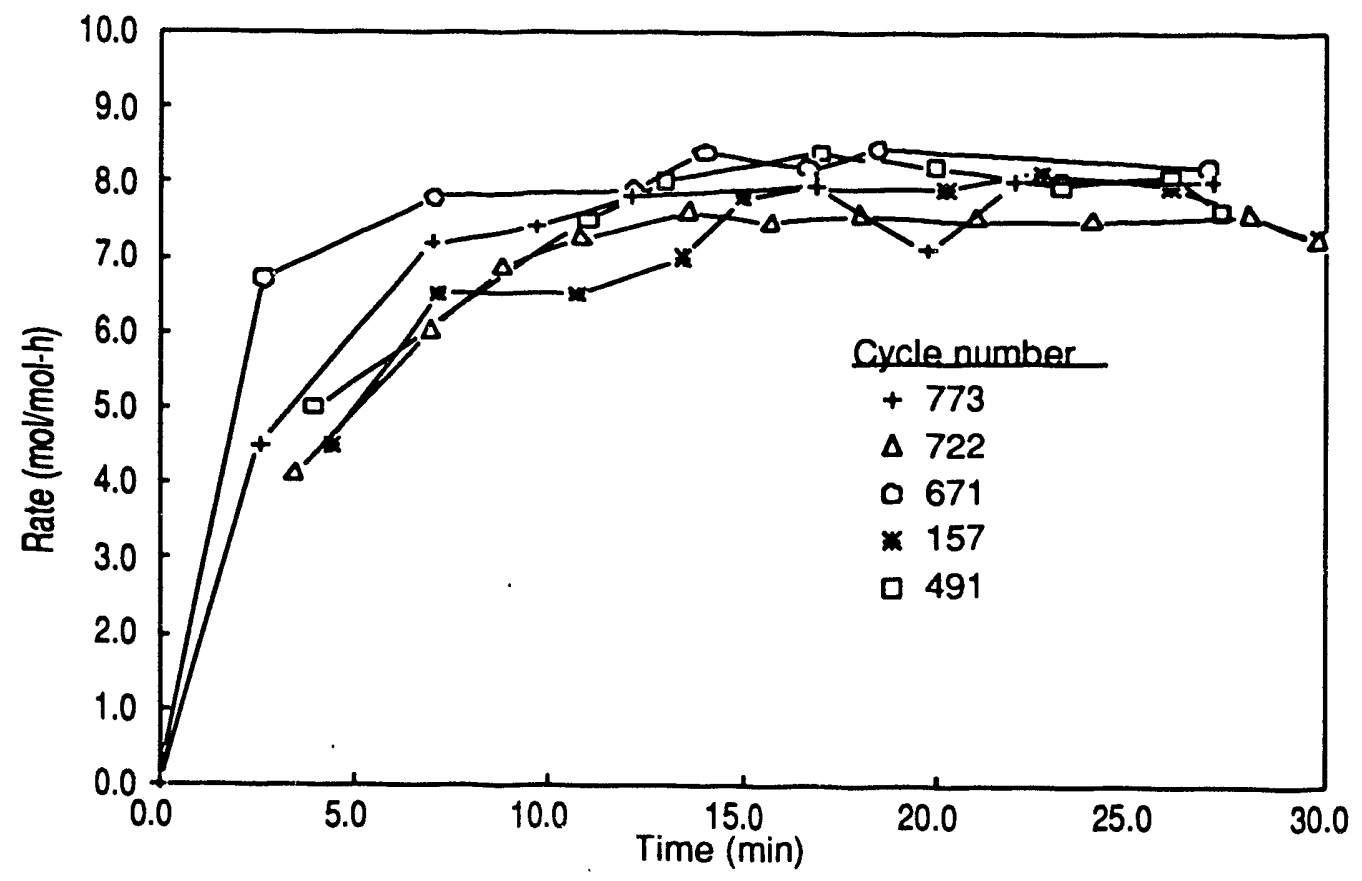

Fig. 8. Adsorption rates of CC180-1580 during cyclic operation.

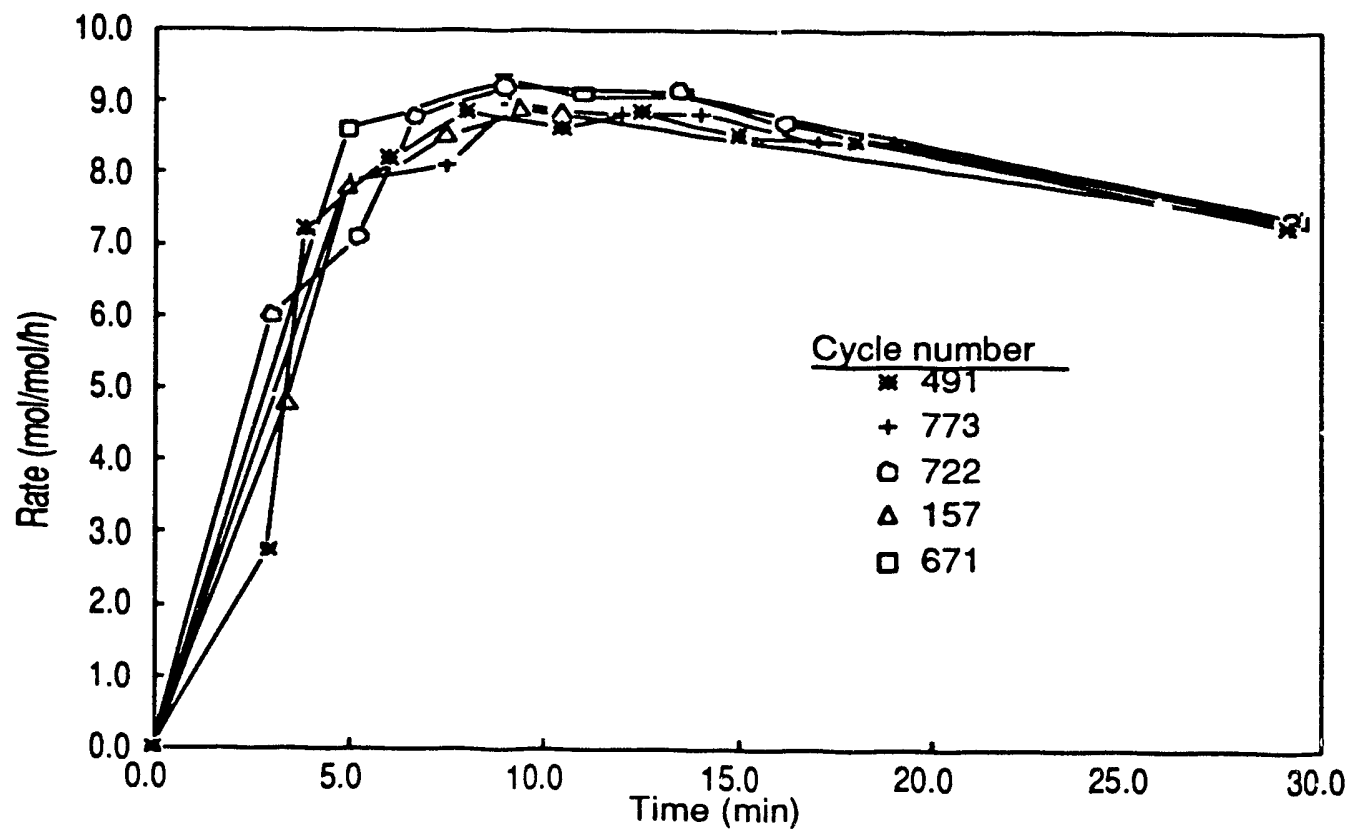

Fig. 9. Desorption rates of CC180-1580 during cyclic operation. 


\subsection{REACTIVITY ANALYSIS}

Solid-gas chemisorption reactions are linited by heat and mass diffusion. Subcooling of the solid adsorbent leads to adsorption reactions, and superheating results in the corresponding desorption reaction. For an energy efficient thermal storage system, however, the degree of subcooling and superheating should be minimal. Therefore, heat and mass transfer resulting from thermal and mass diffusivities is an important process characteristic requiring significant attention in the development process. Heat and mass transfer limitations are traditional problems with solid-vapor thermal processes that have prevented commercial success of most thermal equipment developments until today.

Three different approaches toward effective heat and mass transfer were pursued in parallel: (1) a system in which the complex compound is part of a pumpable slurry, (2) use of a carrier liquid to transport refrigerant to the complex compound, and (3) optimized solid-bed reactors.

\section{Complex Compound Slurry System}

Since it was well known that heat and mass transfer rates of fixed bed reactions are largely dependent on bed thickness and resulting diffusion paths, the first attempt to improve heat and mass transfer properties was made using a slurry consisting of an ammonia permeable liquid and an adsorbent salt that could be pumped across heat transfer surfaces. Several liquids were tested and reaction rates were observed. In one case, an experiment was performed with a 50 wt \% mixture of CC053-1029 and octanol. The mixture was placed in a temperature controlled reactor vessel and was agitated with a magnetic stirrer. The reactor was then connected to an ammonia source at fixed pressure to simulate a fixed amount of superheat, and the ammonia uptake measured by observing the level of liquid ammonia in the ligand column (evaporator). Reaction rates and total amount of ammonia adsorbed were both significantly enhanced. Figure 10 shows that after 5 hours the ammonia uptake of the slurried complex compound is approximately $50 \%$ greater than the uptake with the dry bed system. 


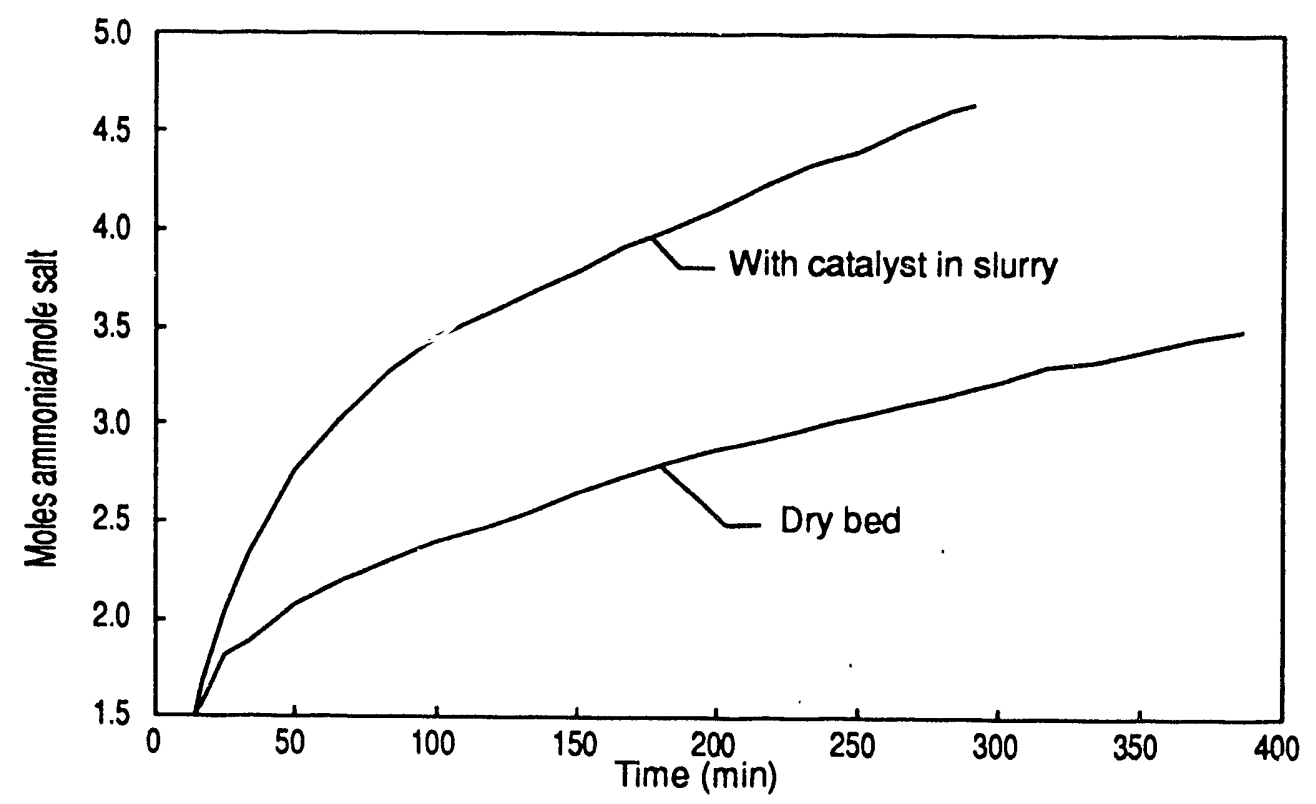

Fig. 10. Adsorption uptake curve for CC480-1110.

Further experimental tests revealed that pumpability of the candidate complex compounds could be maintained throughout the entire sorption process if at least $35 \mathrm{wt} \%$ carrier liquid were used with the adsorbent salts. The major reduction in heat transfer area due to the increased reactivities led to promising economics. The technical problem to be solved centered around slurry conditioning and proper agitation.

Analysis of achievements made after four months development led to the general conclusion that resolution of slurry distribution, agitation, and vapor carryover issues would require an effort beyond the scope the current project. Alternative investigations avoiding slurry mixing problems were continued.

\section{Carrier Liquid}

Diffusivity can be enhanced by mechanically moving the solid adsorbent (as with the slurry concept) or by mechanically forcing a carrier liquid through a fixed bed of adsorbent, thereby enhancing heat transfer and ammonia transport. Transport is effective if the carrier liquid has a high ammonia absorption capacity such that the ammonia 
refrigerant can be absorbed in a conventional liquid-vapor absorber and then released to the coordinative romplex compound as the liquid is pushed through the solid bed. Issues investigated for this concept included solubility of complex compounds in the carrier liquid, solubility of ammonia refrigerant in the liquid, and mechanical designs of the fixed bed including pressure drop of liquid flowing through the bed and containment of solids within the bed.

In order for a liquid to qualify as a refrigerant carrier fluid, it must perform as an ammonia absorbent and therefore be soluble in ammonia; at the same time it should not dissolve significant amounts of adsorbent salt, i.e., it must be inert to the adsorbent. The carrier liquid must have a low vapor pressure relative to the complex compound to avoid excessive carryover (to the refrigeration system) of carrier liquid with ammonia vapor. However, the vapor pressure of the liquid-ammonia solution must be higher than the vapor pressure of the ammoniated complex compound for the concept to be valid, but excessive vapor pressure differences will result in operation with a lean rather than rich carrier liquid. Use of a carrier liquid rich in ammonia is required to reduce the pumping power required to circulate the liquid through the fixed bed of complex compound. The criteria used for evaluation of candidate liquid carriers were:

- Solubility of liquid in adsorbate

- Solubility of adsorbent in the liquid

- Vapor pressure ratio between liquid and the complex compound

- Potential formation of compounds between liquid and adsorbent.

Identification of liquids meeting these criteria proved difficult. The requirement for high refrigerant solubility and low adsorbent solubility leads to the dilemma that liquids which are highly soluble in polar gases such as ammonia and water are also soluble in polar salts. Answers to this problem were found in long chain molecules, i.e. long chain alcohols and ammines. These media show reasonable solubility in low molecular weight polar gases, but are almost inert to most metal inorganic salts. Solubility problems are reduced by using hydroxide, carbo:ate, or phosphate salts rather than bromides, chlorides, 
or chlorates. However, the coordination properties of the later group are superior to those of the first group, and this research focused on finding carrier liquids suitable for use with bromated or chlorinated metal salts.

Investigation of candidate carrier liquids included measurement of solubilities to ammonia and one complex compound forming salt, CC480-1110. The apparatus for measurement of complex compound solubility comprised a temperature-controlled container for the liquid and a magnetic stirrer. Temperature was maintained by a constant temperature bath as shown in Fig. 11. Kriown amounts of salt crystals were added to an Erlenmeyer flask and agitated at room temperature. If saturation was obtained, the liquid was heated to $50^{\circ} \mathrm{C}$ in order to determine the maximum solubility under process conditions. The starting masses were $25 \mathrm{~g}$ organic liquid and $0.03 \mathrm{~g}$ salt, resulting in a minimum concentration of $0.12 \%$ if completely dissolved. Eight liquids were tested and all showed very low solubilities. Results are summarized in Table 1.

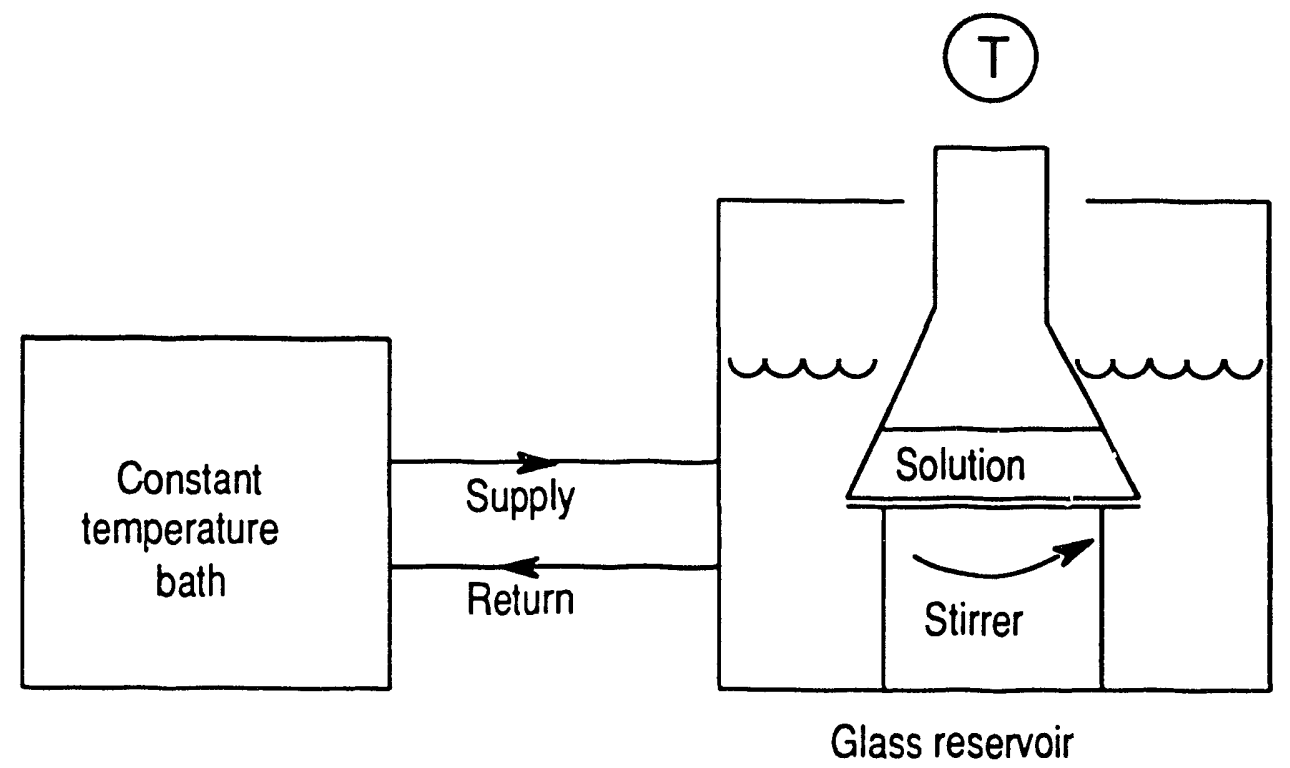

Fig. 11. Schematic of carrier liquid-complex compound solubility test system. 
Table 1. Solubilities of CC480-1110 forming salt in organic liquids.

\begin{tabular}{lrr}
\hline Liquid & $\begin{array}{r}\text { solubility } \\
\text { at } 25^{\circ} \mathrm{C}\end{array}$ & $\begin{array}{r}\text { solubility } \\
\text { at } 50^{\circ} \mathrm{C}\end{array}$ \\
\cline { 2 - 3 } Pentanol & $<0.1 \%$ & $<0.1 \%$ \\
Hexanol & $<0.1 \%$ & $0.2 \%$ \\
Heptanol & $<0.1 \%$ & $<0.1 \%$ \\
Octanol & $<0.1 \%$ & $<0.1 \%$ \\
Di-methyl-phthalate & $<0.1 \%$ & $<0.1 \%$ \\
Di-butylphthalate & $<0.1 \%$ & $<0.1 \%$ \\
Butylether & $<0.1 \%$ & $<0.1 \%$ \\
Ethylene glycol & $0.4 \%$ & $0.8 \%$
\end{tabular}

The solubility of ammonia in the organic solvents is defined by $\mathrm{p}-\mathrm{T}-\mathrm{x}$ (pressuretemperature-concentration) data of the respective solvent-ammonia pair. The $\mathrm{p}-\mathrm{T}-\mathrm{x}$ characteristics were measured for ammonia with propanol, butanol, octanol, butylether, and ethylene glycol. In order to obtain effective mass transfer in the liquid-vapor absorber, the organic-ammonia solution must be cycled around the equilibrium p-T line of the complex compound. The pre-cooled solution entering the absorber must have a lower vapor pressure than the complex compound pressure (which is close to the $\mathrm{NH}_{3}$ evaporator pressure) in order to absorb ammonia. Transfer of ammonia from the ammonia-rich solution to the complex compound requires that the solution vapor pressure be higher than the complex compound vapor pressure at heat rejection temperature. This requirement can be met with all solvents for which p-T-x data were measured. The most desirable solvents are those for which required flow rates and parasitic pump power are lowest. Required flow rate is related to concentrations by

flow $\propto\left(\mathrm{X}_{\mathrm{v}}-\mathrm{X}_{\text {weak }}\right) /\left(\mathrm{X}_{\text {rich }}-\mathrm{X}_{\text {weak }}\right)$

where:

$$
\begin{aligned}
& \mathrm{X}_{\mathrm{v}}=\text { Ammonia concentration in vapor } \approx 1 \\
& \mathrm{X}_{\text {weak }}=\text { Ammonia concentration in weak solution } \\
& \mathrm{X}_{\text {rich }}=\text { Ammonia concentration in rich solution. }
\end{aligned}
$$


High absolute concentrations and large concentration spreads minimize flow rates and pumping power. This consideration led to selection of propanol and ethylene glycol as the most promising solvents for ammonia TES systems. Propanol-ammonia solutions can be operated with ammonia concentrations between 20 and $25 \%$ for TES applications between 0 and $8^{\circ} \mathrm{C}$. At $-30^{\circ} \mathrm{C}$ the absolute ammonia concentration in the solution drops to $\approx 5 \%$ and the usable spread in concentration is only $1 \%$, for acceptable approach temperatures of 3 to $4{ }^{\circ} \mathrm{C}$. Ethylene glycol-ammonia solutions can be operated with concentrations $>30 \%$ for TES between 0 and $8^{\circ} \mathrm{C}$, and at $-30^{\circ} \mathrm{C}$ the concentration spread-with 3 to $4^{\circ} \mathrm{C}$ approach temperature-is $1.5 \%$ with an absolute concentration $\approx$ $12 \%$.

The results indicate that the TES concept using a carrier liquid has greater promise at higher TES temperatures, particularly above $\approx 0^{\circ} \mathrm{C}$. At lower temperatures the parasitic pump power requirements become significant. A $-30^{\circ} \mathrm{C}$ TES system can only be operated with ethylene glycol solvent, and the concentration spread is very low, requiring very high pumping rates. A $-40^{\circ} \mathrm{C}$ TES system using organic catalytic solvents does not appear possible at this time.

An experimental investigation of bed design and operating characteristics was conducted. After an initial experiment with $\mathrm{CaCO}_{3}$ and water to determine design information, an apparatus for investigation of flow, bed stability, and pressure drop was constructed. The system consisted of a $2.5 \mathrm{~cm}$. (1 in.) ID glass column, a pump loop, and refrigerant (ammonia) gas loop. The temperature of the solvent-ammonia solution was maintained by a constant temperature bath. A mixing container with solution was immersed into the bath. The glass column was equipped with a wire mesh screen holding a layer of adsorbent salt. A photograph of the test apparatus is shown in Fig. 12.

Complex compound CC180-1580 was used as the adsorbent salt. This salt was selected because the equilibrium vapor pressure of the complex compound is close to $1 \mathrm{bar}$ at room temperature. Butanol was used as the car rier fluid. Ammonia was introduced into the mixing vessel such that an ammonia-rich solution of butanol-ammonia could be pumped through the adsorbent. The adsorbent was wetted with butanol prior to being loaded into the column. This procedure allowed for determination of the packing difference between 


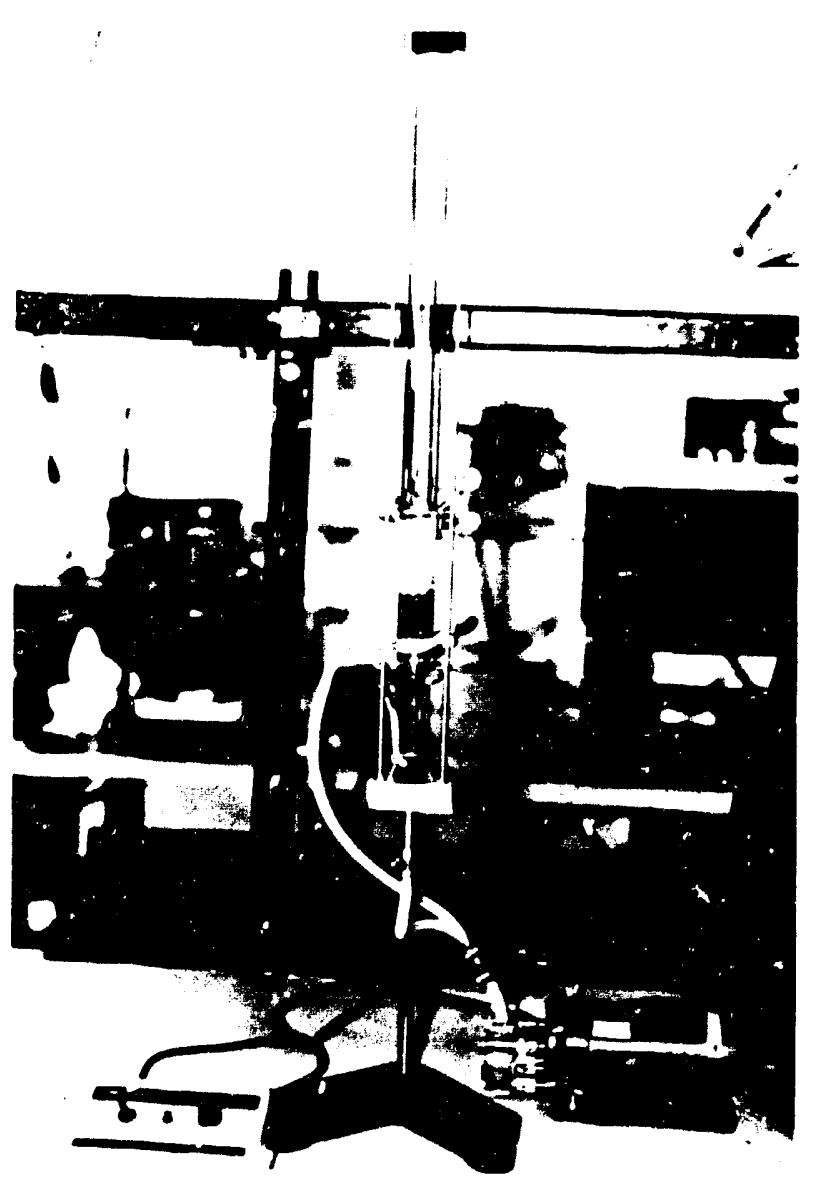

Fig. 12. Carrier liquid proof-of-feasibility apparatus.

ammoniated and non-ammoniated adsorbent. The initial layer thickness of CC180-1580 was $10 \mathrm{~cm}$. After ammoniation the column height (adsorbent) increased to $11.5 \mathrm{~cm}$. Qualitative temperature rise in the complex was observed during ammoniation. Flow rates were varied between 100 and $225 \mathrm{ml} / \mathrm{min}$ at head pressures between 0.5 and $1.2 \mathrm{bar}$. This experiment provided qualitative proof that a liquid carrier could be used to transport ammonia to an immobilized bed of complex compound.

In summary, the use of a carrier liquid and complex compounds in TES systems using ammonia refrigerant is possible. Sorption power of the carrier liquids is limited, however, such that reasonable ammonia uptake and transport can only be achieved at ammonia equilibrium temperatures of $=0^{\circ} \mathrm{C}$ or higher. Lower iemperatures result either in 
low ammonia transport and excessive parasitic pump power requirements for the carrier liquid, or, for liquids that showed high sorption capacity at low temperatures, the salt dissolves in the carrier liquid as it desorbs ammonia and is carried into the liquid vapor absorber. Since the technical approach using a liquid carrier fluid as the ammonia transport mechanism does not address the refrigeration target market with its typical operating temperatures at or below $-7^{\circ} \mathrm{C}$, investigation of this particular approach was discontinued.

\section{Optimized Solid-Bed Reactors}

The third approach to optimize heat and mass transfer in solid-vapor complex compounds was investigated in parallel to the liquid-based and slurry-based approaches. The approach was based on a breakthrough in complex compound reactor development achieved in a reported project. ${ }^{2,3}$ Solid-vapor reactivities with energy densities of $2 \mathrm{~kW} / \mathrm{kg}$ and higher had been achieved at approach temperatures (devis:ion from equilibrium) of only $8^{\circ} \mathrm{C}$ to $11^{\circ} \mathrm{C}$. While these approach temperatures and reactivities were a significant breakthrough for solid-vapor heat pumps, applicability to boundary conditions suitable for thermal storage required verification. Discharge and charge periods of thermal storage systems are typically a duration of several hours and therefore, one order of magnitude larger than heat pump cycles. This eases the reaction rate requirement accordingly by about one order of magnitude. The allowable approach temperatures for a cost effective thermal storage system, however, are much lower than those tolerable in heat activated heat pumps.

Therefore, the dry ted complex compound density control technique, which led to extremely promising heat pump reactor performances, was adapted to thermal storage conditions of lower reaction rates and much lower approach temperatures. Two candidate complexes were investigated with respect to their desorption and adsorption reactions. Reaction rates of $0.7 \mathrm{~mol} / \mathrm{mol}-\mathrm{h}$ to $1.2 \mathrm{~mol} / \mathrm{mol}-\mathrm{h}$ constitute the desired range of reactivity. Figure 13 shows the results obtained with a candidate complex compound. Complex CC180-1580 can maintain a desorption rate of $1.5 \mathrm{~mol} / \mathrm{mol}-\mathrm{h}$ for a period of 220 minutes at approach temperatures of $4^{\circ} \mathrm{C}$. This corresponds to a mole number change of 5.5 , which 


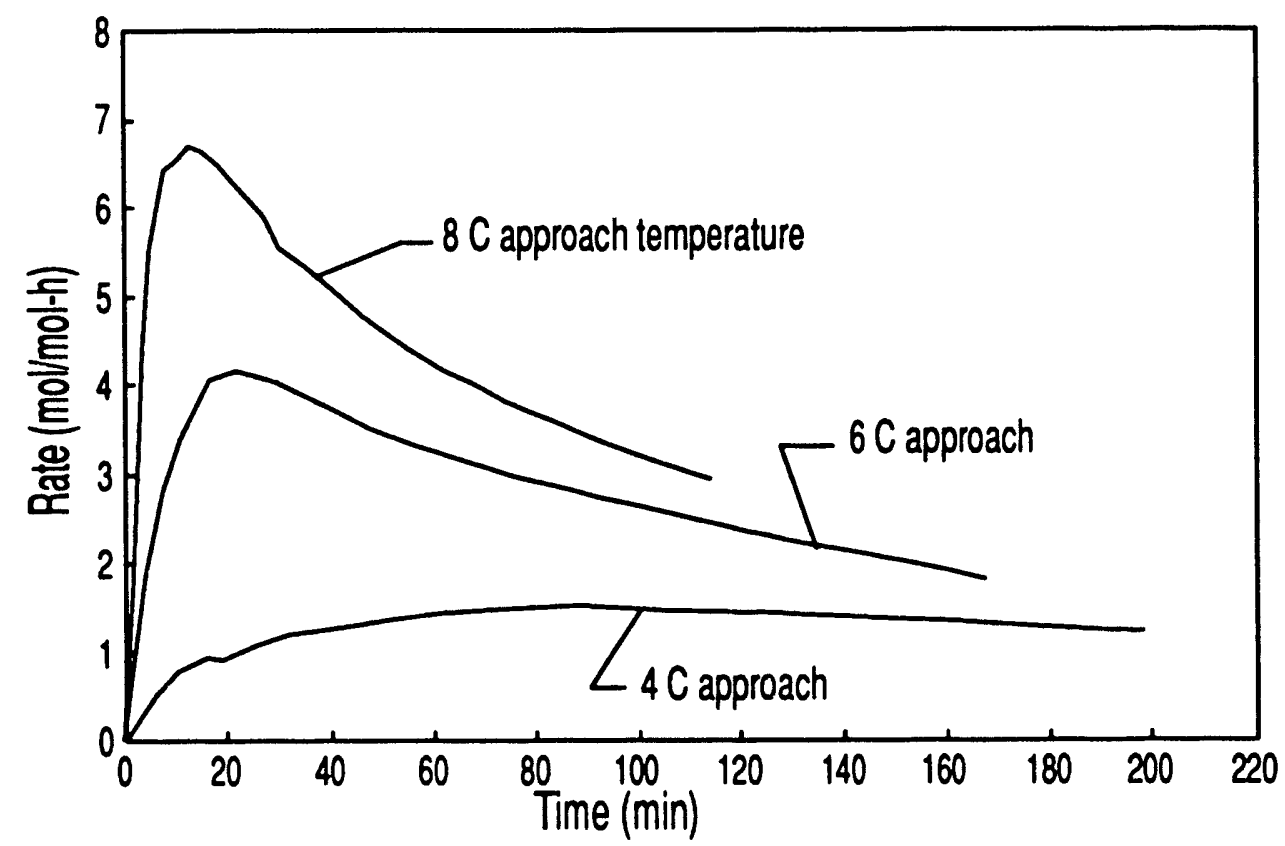

Fig. 13. Reactivity of CC180-1580.

is $75 \%$ of the theoretical coordination sphere for this complex compound. Greater approach temperatures permit higher rates or slightly larger mole number utilization. Results for adsorption are nearly identical.

After approximately 7 months of work on this project, the dry-bed reactor concept was selected as the concept of choice for further development. This selection was made not because of insurmountable problems with the two liquid concepts, but because of technical, economic and practical advantages of the dry-bed system. Selection considerations included the following:

1. Cost: The dry-bed concept using packed bed heat exchangers is less expensive. Projected costs for a complete dry-bed system (without installation) are about $\$ 200 /$ ton-h, with $\$ 72$ of this being heat exchanger costs. Heat exchanger costs for slurry and solvent concepts are optimistically estimated to be $\$ 85 /$ ton-h. The balance of the system will also be more costly for the slurry and solvent concepts. The slurry system will require slurry pumps and a slurry distribution mechanism. 
The solvent system will require a solution pump, solid-liquid phase separator (such as membranes), and heat exchangers for subcooling.

2. Performance: A dry bed heat exchanger exceeding performance goals of 4.8 moles refrigerant per mole of adsorbent adsorbed or desorbed in a four hour period was demonstrated. These goals were met with approach temperatures between 3 and $5^{\circ} \mathrm{C}$. The slurry and solvent concepts require additional temperature drops to drive adsorption and desorption into the liquid carrier or solvent, and will require more heat transfer surface or a greater temperature drop to achieve the same performance.

3. Development risk: The dry bed cool storage concept is very simple. The primary research and development issues were finding suitable complex compounds and suitable heat exchanger designs, both of which have been met. The risk associated with development of an operating system with adequate performance is very low.

The technical risks with slurry and solvent concepts are significant. Appropriate carriers and solvents must be identified and proven to be stable. Solvent concepts require low pressure drop reactant beds with little change in bed properties over time. Reliable slurry pumps must be identified and proven.

4. Integration with refrigeration systems: The dry bed concept can be easily coupled to an ammonia refrigeration system with no concern about contaminating ammonia with other chemicals. The solvent and slurry systems will require fluids with very little carryover into the ammonia refrigeration system, or will require process isolation with heat transfer coupling to the load. A heat-transfer coupled system will increase cost and required approach temperatures.

5. Simplicity and reliability: The dry bed cool storage system has no moving parts and should be very reliable. Solvent and slurry concepts are much more complex 
and have more components, such as pumps, that require maintenance and are subject to failure.

6. Industry preference: The different concepts for a complex compound chill storage system were discussed with refrigeration equipment manufacturers and experts in refrigeration system design. It was the general opinion that a dry bed reactor development is the most reasonable approach to a viable product, and would be most readily accepted by manufacturers and users. 


\subsection{OPTIMIZATION OF SOLID-BED REACTORS FOR TES}

Remaining work under this project consisted of partial optimization of the solidbed heat exchanger for thermal storage, and demonstration of performance on a larger scale. Issues addressed included: (1) quantification of coordination sphere utilization as a function of heat rejection temperature, loading density, and approach temperature; (2) proper complex compound conditioning for maximum coordination sphere utilization; and (3) operating modes.

\section{Complex Compound Preconditioning}

Early in the investigation of the dry-bed system it became apparent that coordination sphere utilization was greatly affected by the manner in which the initial adsorption with the complex compound was conducted. Rapid initial adsorptions were required for proper coordination sphere utilization. Specifications for preconditioning were developed which resulted in repeatable results with high coordination sphere utilization. Later in the project, it was discovered that saturation of the complex compound with refrigerant for a prolonged period of time resulted in superior conditioning. Although saturation periods of several hours appear to be sufficient, full investigation of the necessary conditions and times was not completed. Figure 14 shows reaction rates and mole number change $(\Delta N)$ without preconditioning, with rate preconditioning, and with soak preconditioning. The initial bench-scale adsorption (line 2) was following partial rate preconditioning. The usable portion of the coordination sphere increases to nearly $85 \%$ following soak preconditioning. This is a process that will happen automatically during construction and installation of a TES system. The complex compound will be ammoniated immediately following reactor assembly, to add mechanical stability to the salt load. The time between reactor assembly and operation will be a soak period.

\section{Heat Exchanger Loading Density}

The amount of ammonia adsorbed and desorbed decreases as packing density of the complex compound in the heat exchanger is increased. Results of laboratory-scale experiments with CC180-1580 at two loading densities are illustrated in Fig. 15. Except 


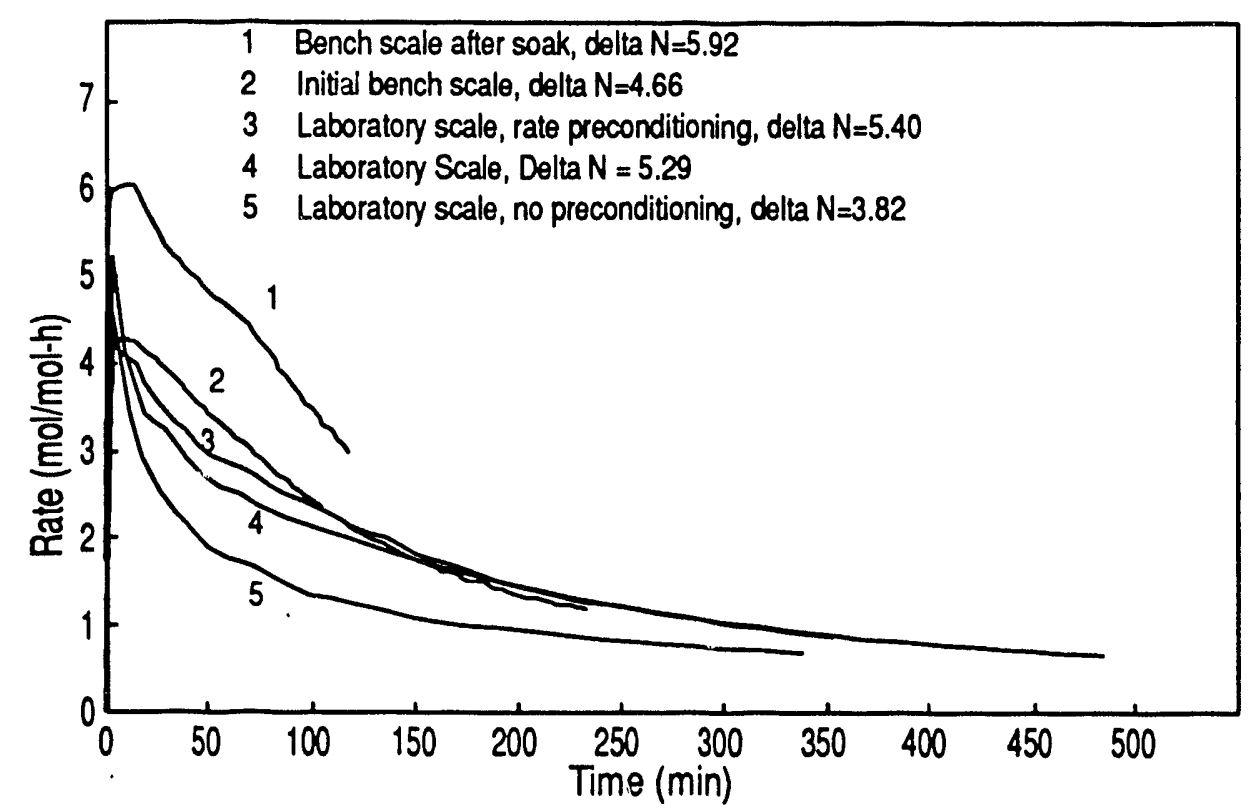

Fig. 14. Reaction rates and coordination sphere utilization with various complex compound conditioning. Data are for CC180-1580 adsorptions at $45^{\circ} \mathrm{C}$ and $6^{\circ} \mathrm{C}$ approach temperature.

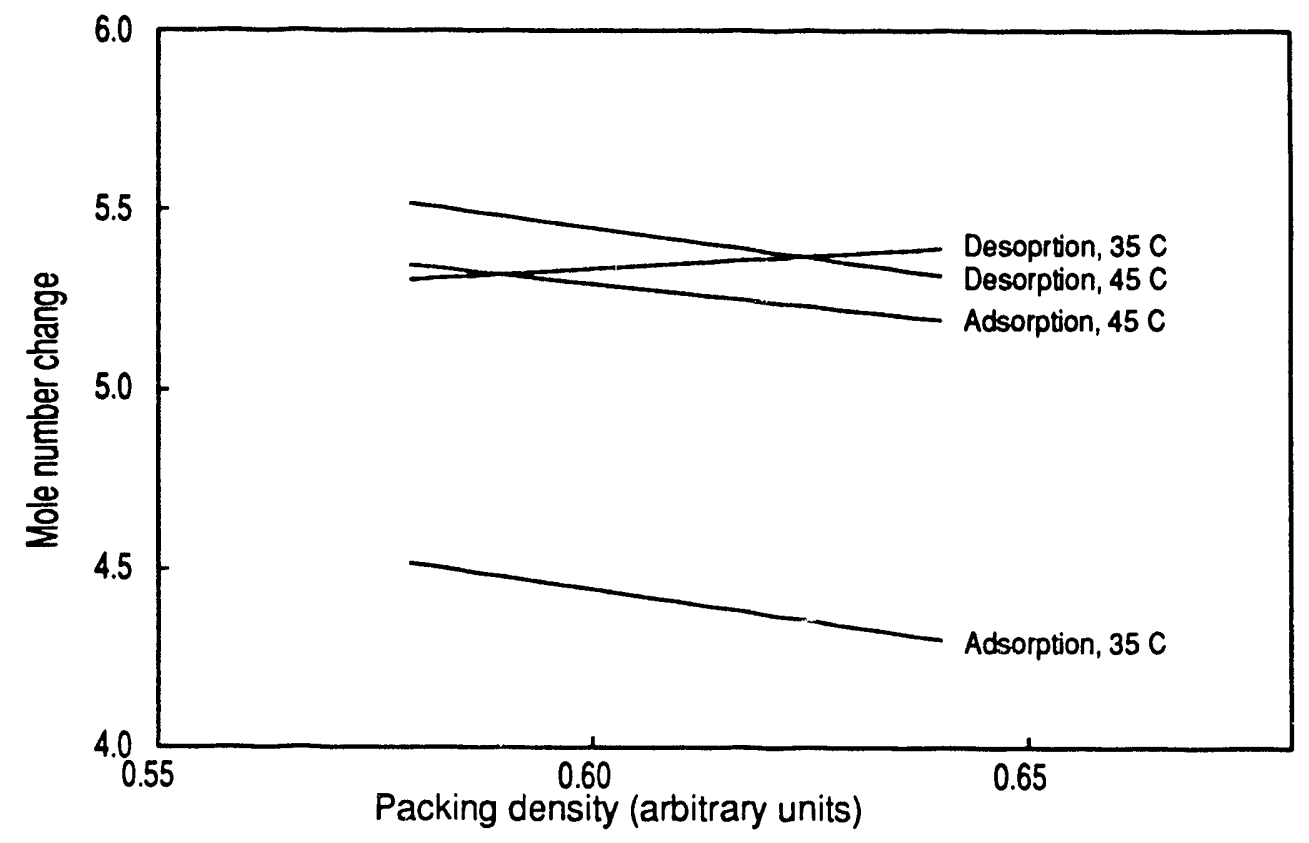

Fig. 15. Usable mole number change for $\mathrm{CC} 180-1580$ with $6^{\circ} \mathrm{C}$ approach temperature. 
for anomalous data for the desorption at $35^{\circ} \mathrm{C}$ heat rejection, refrigerant holding capacity increases at lower loading densities. However, the important optimization parameter is cost per unit energy storage. Lower loading densities require less complex compound but may require more heat exchange surface and a larger containment. Figure 16 shows normalized reactor costs for the data of Fig. 15. The lower densities, while increasing the refrigerant holding capacity, also result in increased cost per unit of storage capacity. The cost data used to generate this plot are a complex compound cost of $\$ 2.01 / \mathrm{kg}(\$ 0.91 / \mathrm{lb}$.) and reactor cost (heat exchanger, and other internals, vessel, and labor) of $\$ 71.50 / \mathrm{m}^{3}\left(\$ 2.03 / \mathrm{ft}^{3}\right)$ of complex compound in the reactor. These data are sensitive to the ratio of complex compound cost to hardware cost, and will be reevaluated when system costs are more accurately determined. Current indications are that loading densities should not be decreased to increase coordination sphere utilization. Increased loading densities are not considered practical due to mechanical considerations.

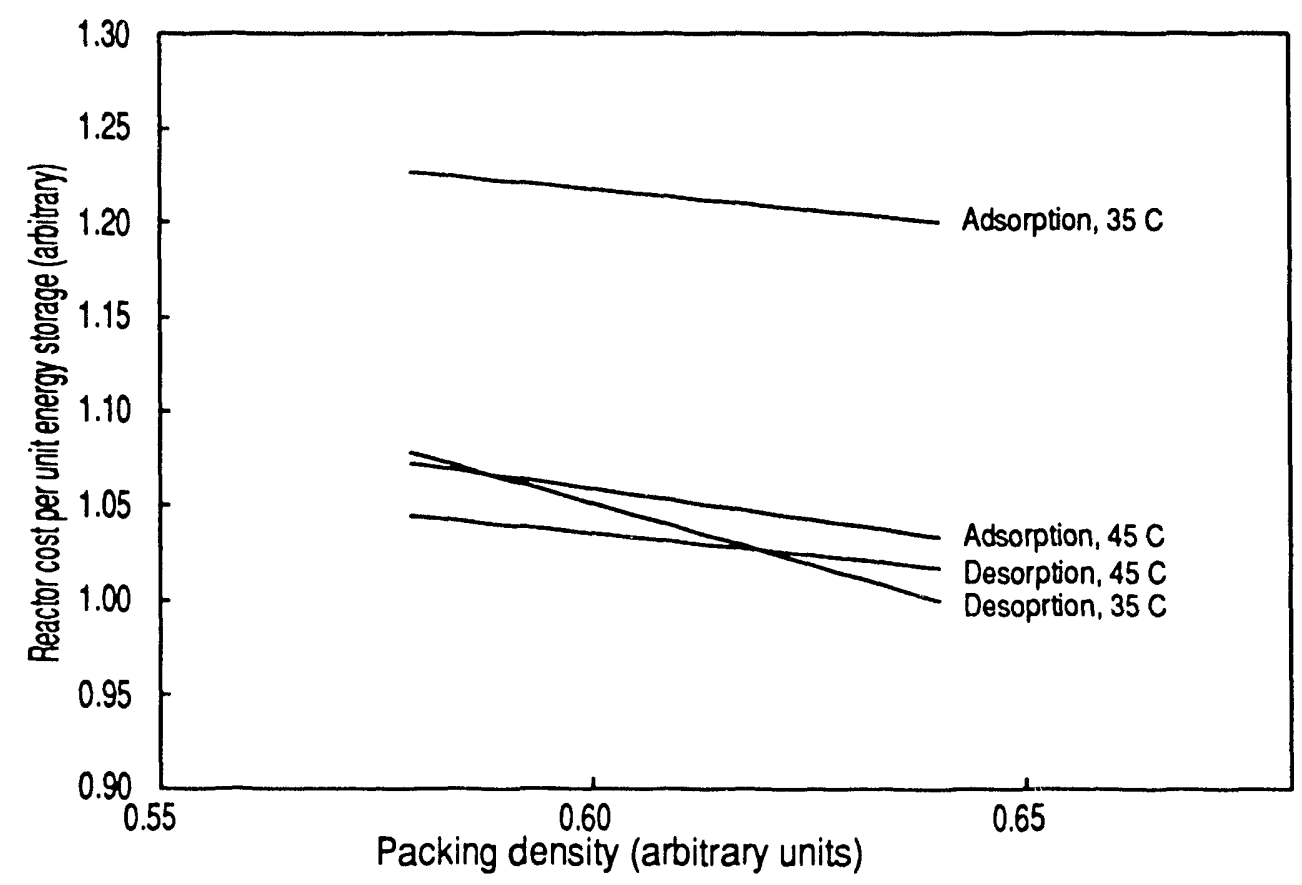

Fig. 16. Cost of reactor internals and vessels for thermal storage using CC180-1580. 


\section{Heat Rejection Temperature and Approach Temperature}

The amount of refrigerant that can be cyclically adsorbed and desorbed in a TES system depends on the heat rejection temperature and approach temperature. Figure 17 shows the usable coordination range for adsorption and desorption as a function of approach temperature. The line shown is a linear least-squares fit to the adsorption data (shown as circles) and the other line is a linear fit to desorption data, indicated here by triangles. Although the linear fit is poor it is obvious that decreasing approach temperatures consistently result in decreasing storage utilization. These data are for sorptions at $35^{\circ} \mathrm{C}$; higher sorption (heat rejection) temperatures result in better utilization as indicated by the data of Fig. 18. Linear fits to adsorption and desorption data are shown as before to make trends more apparent. The allowed approach temperature during storage discharge (adsorption) depends on the refrigeration temperature that must be maintained. An approach temperature of $4^{\circ} \mathrm{C}$ will allow $-28^{\circ} \mathrm{C}$ refrigeration with $\mathrm{CC} 180-1580$. A minimum discharge coordination sphere utilization of 5.18 moles is indicated by Fig. 17, with greater utilization at higher reject temperatures or approach temperatures. The

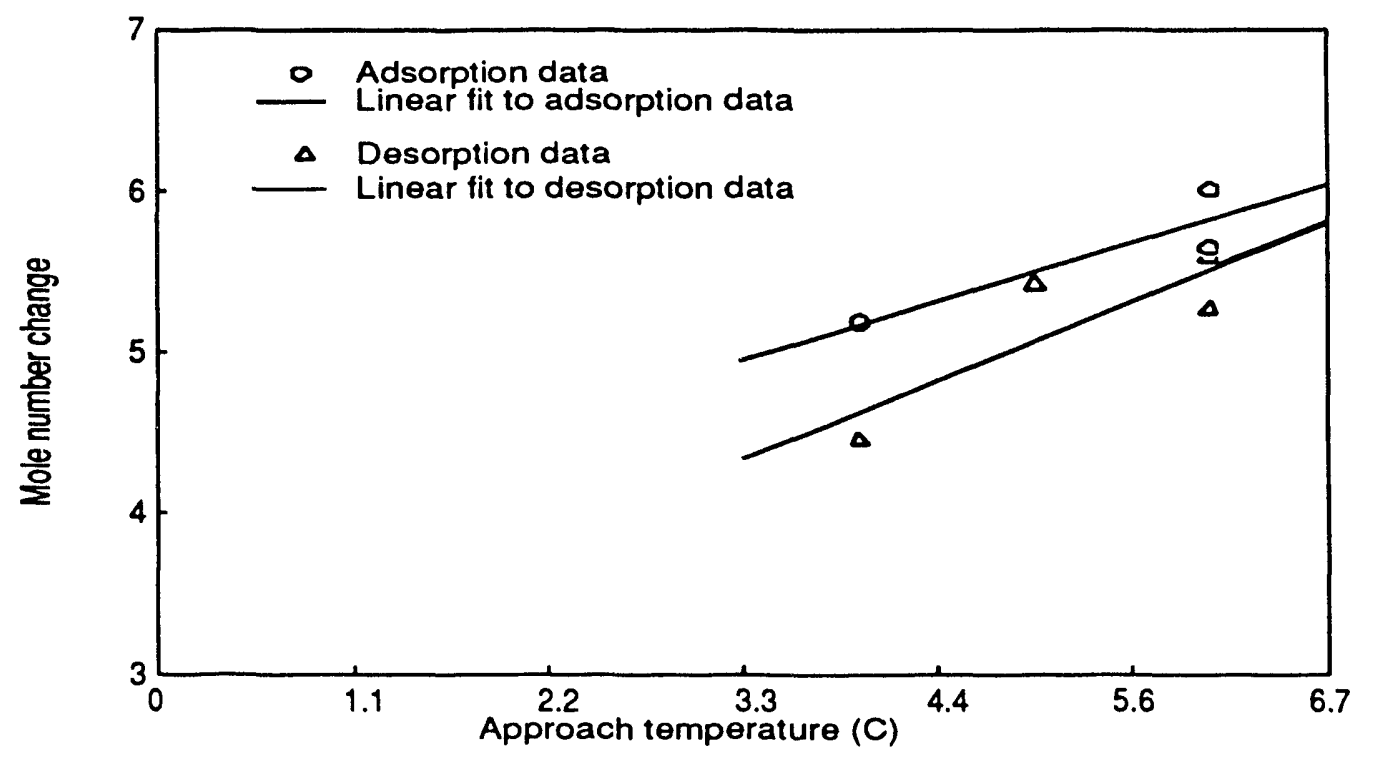

Fig. 17. Coordination sphere utilization as a function of approach temperature for $\mathrm{CC} 180-1580$ at $35^{\circ} \mathrm{C}$ heat rejection. 


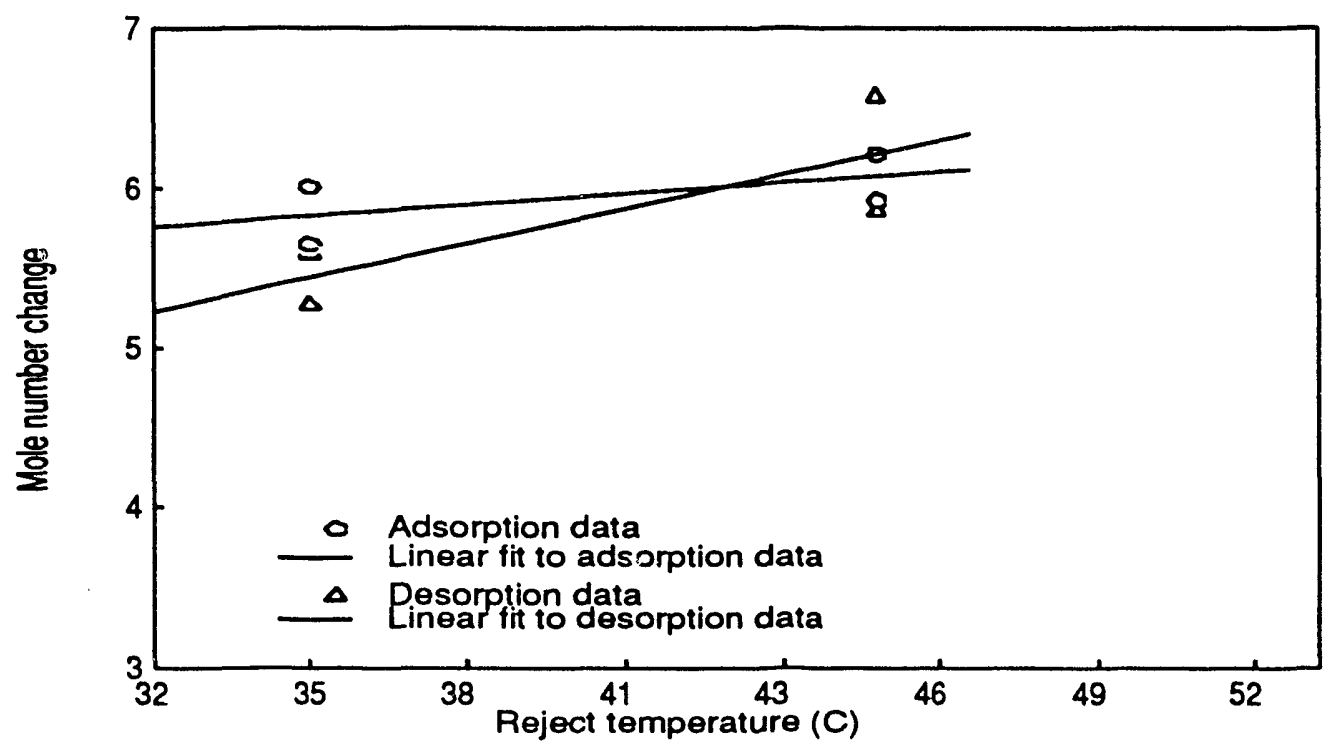

Fig. 18. Coordination sphere utilization as a function of heat rejection temperature for CC180-1580 at an approach temperature of $16^{\circ} \mathrm{C}$.

approach temperature during charging (desorption) affects the power required for the system. Low approach temperatures are desired. However, desorption at $35^{\circ} \mathrm{C}$ with $4^{\circ} \mathrm{C}$ approach is not completely relevant because all desorptions will operate at low approach temperature until the final fraction of adsorbed ammonia is removed. Realistically, these results indicate at least 5.5 moles of ammonia will be removed during system charging.

\section{Operating Modes}

The reactivity of complex compounds is not constant over the entire coordination sphere. Desorptions exhibit slower reaction rates (at fixed approach temperature) as the refrigerant concentration decreases, while adsorptions show reduced reactivity at high refrigerant loading. The preferred operating mode of TES systems is influenced by this characteristic. The complex compound working media in a TES system will typically be contained in a number of vessels which can be brought on line sequentially or simultaneously. Simultaneous actuation will result in reactor capacity initially large compared to compressor or evaporator capacity, and the latter elements will determine 
system power. For most of the charge or discharge cycle, the power will be nearly constant as dictated by compressor or evaporator sizing (and cooling load during discharge). From the point of view of the complex compound, most of the cycle will be conducted at constant reaction rate. Conversely, sequential activation of complex compound reactors will maintain reactor desorption or adsorption capability small compared to compressor or evaporator capacity; system suction or discharge pressure will be controlled by the compressor and constant-pressure operation will be approximated. Capacity will be maintained by adding additional reactors as power from each decreases.

Laboratory tests have been conducted at constant pressure and constant reaction rate conditions to simulate these two possible operating modes. Constant pressure operation generally gives better performance than constant rate operation. Figure 19 shows results for adsorptions at constant pressure and constant rate. In this example the constant rate could not be maintained (with a maximum approach temperature of $6^{\circ} \mathrm{C}$ ) beyond 4.5 hours $(\Delta \mathrm{N}=4.5)$ and the adsorption was continued at constant pressure to 8 hours. After 8 hours a $\Delta N$ of 5.2 moles was achieved, compared to $\Delta N$ of 5.3 after 6 hours for the

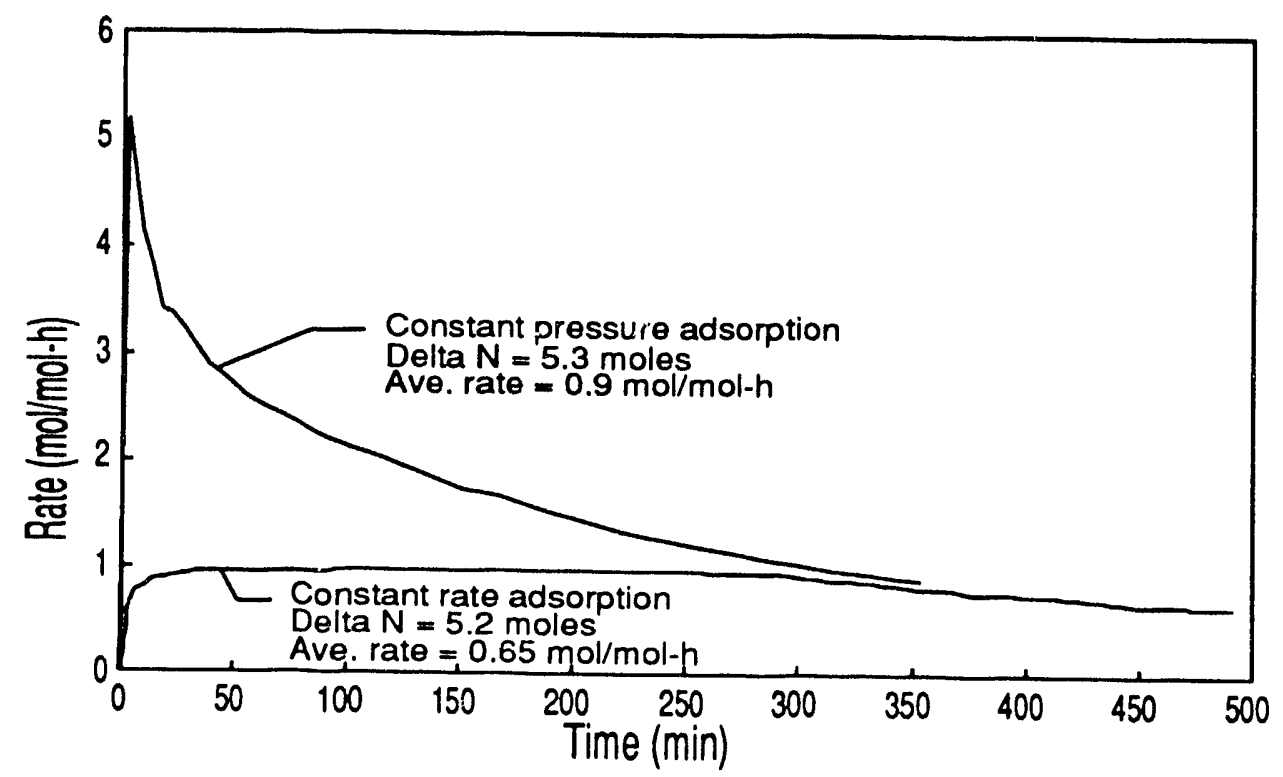

Fig. 19. Comparison of constant rate and constant pressure adsorptions of $\mathrm{CC} 180-1580$ at $45^{\circ} \mathrm{C}$. Maximum approach temperature is $6^{\circ} \mathrm{C}$. 
constant pressure test. The final ammonia adsorption was not significantly different. The true comparison between constant rate and constant pressure operation must be made at 4.5 hours when the target rate of $1 \mathrm{~mol} / \mathrm{mol}$-h could no longer be maintained, compared to 5 hours when the average rate of the constant pressure was $1 \mathrm{~mol} / \mathrm{mol}-\mathrm{h}$. The difference in $\Delta \mathrm{N}-4.5$ moles versus 5.0 moles-is significant. These results indicate that sequential reactor activation to approach constant pressure operation will give maximum performance. Operational flexibility is also obtained if all reactors are not activated simultaneously because load can be increased by activation of additional reactors. A control scheme in which reactors are brought on-line in response to load appears to be optimal.

\subsection{BENCH-SCALE DEMONSTRATION}

The complex compound $-28^{\circ} \mathrm{C}$ chill storage system was demonstrated at a scale of approximately 1 ton-h capacity (bench scale). The system consisted of two reactor vessels each containing $7900 \mathrm{~g}$ of complex compound forming salt, and an evaporator/condenser (ligand column). Reactor vessels are $25 \mathrm{~cm}$. (10-in.) nominal

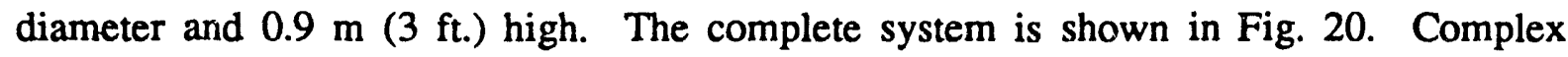

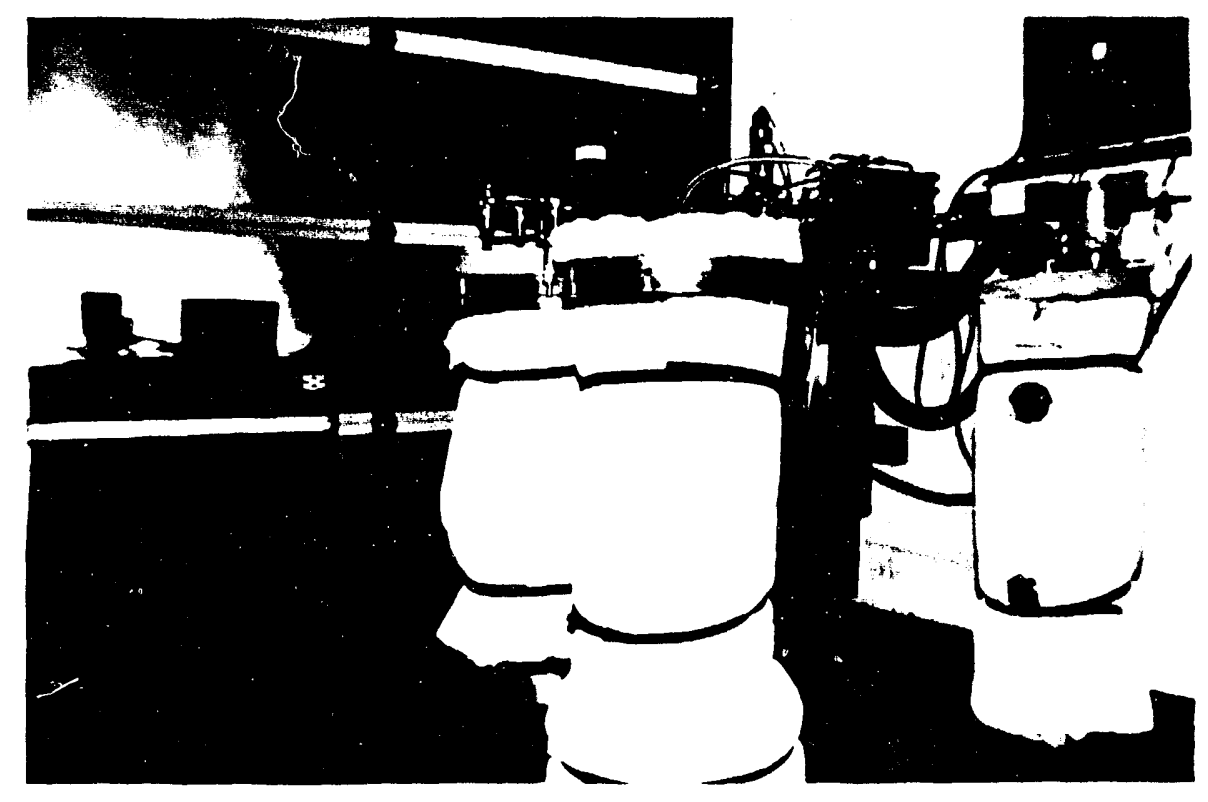

Fig. 20. Bench-scale (1 ton-h) chill storage system. 
compound reactors are in foreground, and the ligand column is against the wall. Instrumentation and data acquisition were provided to allow continuous recording of system pressure, temperature in and out of both reactors and the ligand column, total reactor power, ligand column power, and ammonia vapor mass flow rate.

Performance of the bench-scale chill storage system was superior to that of smaller-scale experiments conducted earlier (after bench-scale reactors were adequately conditioned by a soak period in the fully adsorbed state). Figures 21 and 22 show reaction rates for adsorptions and desorptions, respectively. Plotted in each figure are bench-scale rates at two approach temperatures, and laboratory-scale rates at one approach temperature for comparison. Bench-scale reaction rates and mole number change exceeded those of la soratory-scale tests for both adsorptions and desorptions. The bench-scale system maintained superior results at lower approach temperatures. A summary of relevant benchscale tests is presented in Table 2.

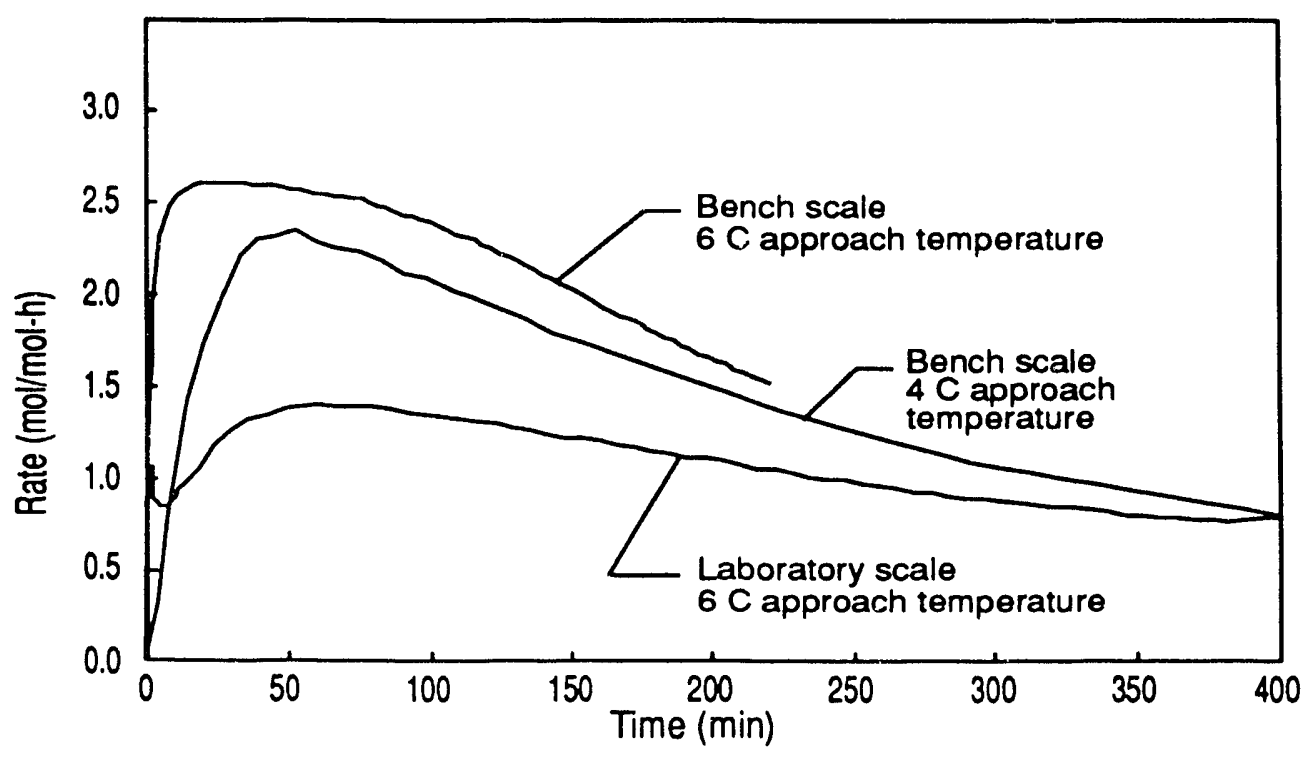

Fig. 21. Desorptions at $35^{\circ} \mathrm{C}$ in laboratory scale $(0.002$ ton-h) and bench scale (1 ton-h) tests. 


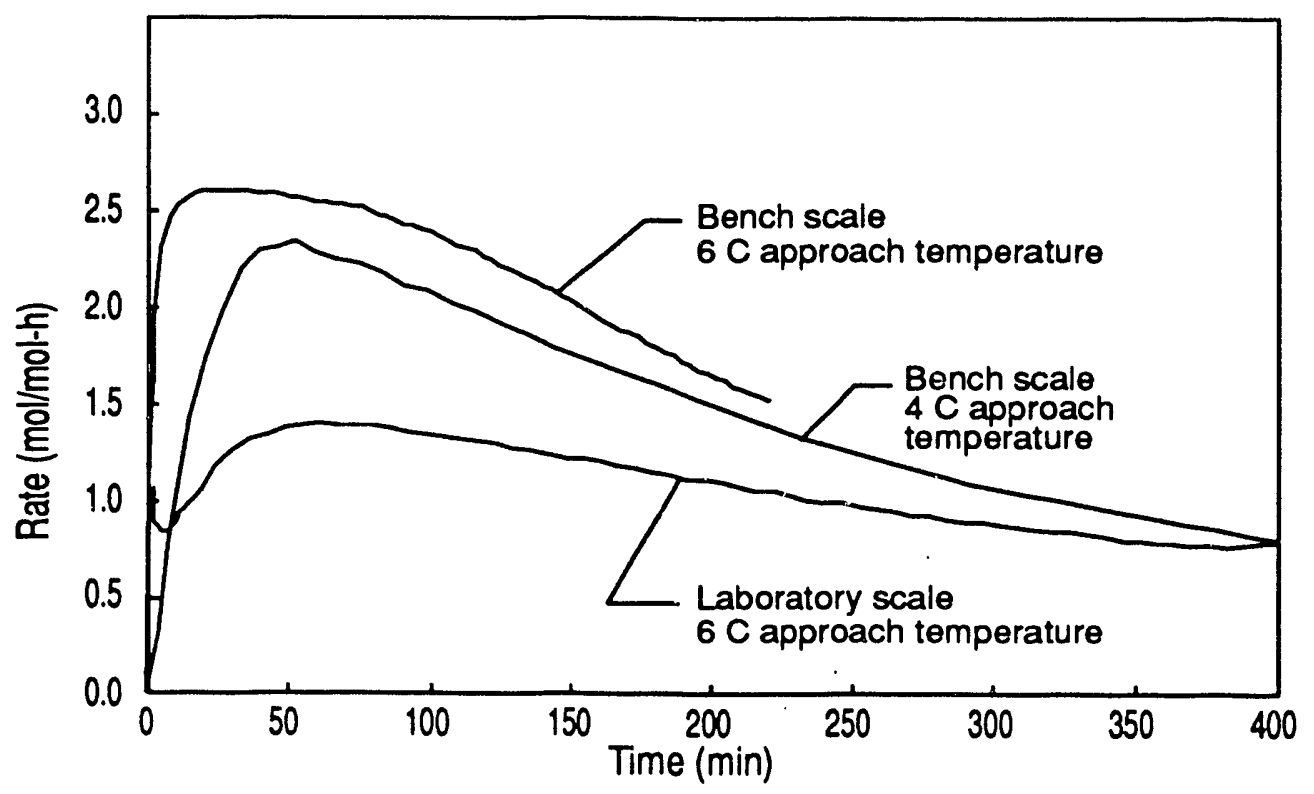

Fig. 22. Desorptions at $35^{\circ} \mathrm{C}$ in laboratory scale $(0.002$ ton-h) and bench scale $(1$ ton-h) tests.

Table 2. Coordination sphere utilization at various TES conditions

$\begin{array}{lcccc}\text { Reaction } & \begin{array}{c}\text { Reactor } \\ \text { number }\end{array} & \begin{array}{c}\text { Temperature } \\ \left({ }^{\circ} \mathrm{C}\right)\end{array} & \begin{array}{c}\text { Approach } \\ \text { temperature } \\ \left({ }^{\circ} \mathrm{C}\right)\end{array} & \begin{array}{c}\text { Mole n } \\ \text { change }\end{array} \\ \text { Adsorption } & 1 & 45 & & \\ \text { Desorption } & 1 & 45 & 6 & 5.92 \\ \text { Adsorption } & 1 & 35 & 6 & 5.85 \\ \text { Desorption } & 1 & 35 & 6 & 6.00 \\ \text { Adsorption } & 1 & 35 & 6 & 5.59 \\ \text { Desorption } & 1 & 35 & 4 & 5.18 \\ \text { Desorption } & 2 & 45 & 4 & 4.46 \\ \text { Adsorption } & 2 & 45 & 6 & 6.57 \\ \text { Desorption } & 2 & 35 & 6 & 6.21 \\ \text { Adsorption } & \text { both } & 35 & 5-6 & 5.42 \\ \text { Desorption } & \text { both } & 35 & 6 & 5.64 \\ \end{array}$




\subsection{FACTORY ASSEMBLY}

Previous work described in this report supported laboratory performance measurernent, scale-up to 1 ton-h in the laboratory, and laboratory cycle testing. Factory construction and testing of a 4 ton-h sorber are described in this section. Objectives were (1) to verify scaleability of TES sorbers and (2) to miasure performance of a factoryassembled sorber.

A sorber with nominal capacity over 4 ton-h $[0.6 \mathrm{~m}(2 \mathrm{ft}$.) diameter by $1.5 \mathrm{~m}(5$ ft.) high] was built at standard Refrigeration in Melrose Park, Ilinois. Project budget and available utilities were not adequate for extended testing, and desorption (chill storage charging) testing under actual chill-storage conditions was impossible. However, sufficient testing was performed to validate earlier laboratory results. Adsorption (chill storage discharge) was found to be comparable to laboratory tests for the first adsorption at chill storage conditions, with adsorption of 4.5 moles of ammonia per mole of salt. Prior laboratory tests have shown adsorptions increase to 5.5 moles after several adsorptiondesorption cycles; but this could not be confirmed because subsequent cycling of the factory sorber was not performed. Desorption performance was equivalent to laboratory results it similar conditions, although chill storage conditions were not simulated.

\section{Reactor Design and Construction}

The complex compound reactor was designed and constructed using industry standard practices for tube-in-shell heat exchangers. The vessel was designed, fabricated, tested, and stamped in accord with the ASME Boiler \& Pressure Vessel Code. Pressure ratings are conservatively high. Maximum working pressures are $31 \mathrm{bar}$ (450 psig) shell side and 9 bar (125 psig) tube side.

The vessel was a cylindrical shell $0.6 \mathrm{~m}$ (24 in.) nominal diameter and $1.5 \mathrm{~m}$ (60 in.) long. Internal heat exchanger modules were connected to support sheets at each end, pald baffles in the heads were used to give 6 module-passes. One hundred thirty-four modules were used internal to the vessel. Heat transfer fluid to provide or remove heat during adsorptions or desorptions passes t'rough the modules. Ammonia adsorption and 
desorption occurs on the shell side of the reactor. The reactor contains $97 \mathrm{~kg}$ (213 pounds) of the unammoniated salt for forming complex compound CC180-1580. This size provides $\approx 4$ ton-h of chill storage at $-28^{\circ} \mathrm{C}$. Figure 23 is a photograph of the completed reactor prior to insulation.

Reactor construction, including loading of complex compound was performed on the factory floor at Standard Refrigeration under actual factory conditions. All steps of the process were performed by Standard employees normally involved in heat exchanger production. Personnel performing salt loading operations were provided with training by Rocky Research technicians. Prototype equipment for loading complex compound was initially constructed at Rocky Research, but the apparatus was modified and rebuilt by Standard Refrigeration.

\section{Testing and Performance}

Ammoniation and testing of the reactor was performed at Standard Refrigeration Facilities. Ammnniztion was performed with the reactor cooled by water pumped from a 550 gallon trough, through the reactor, and back to the trough. Ammonia cylinders were

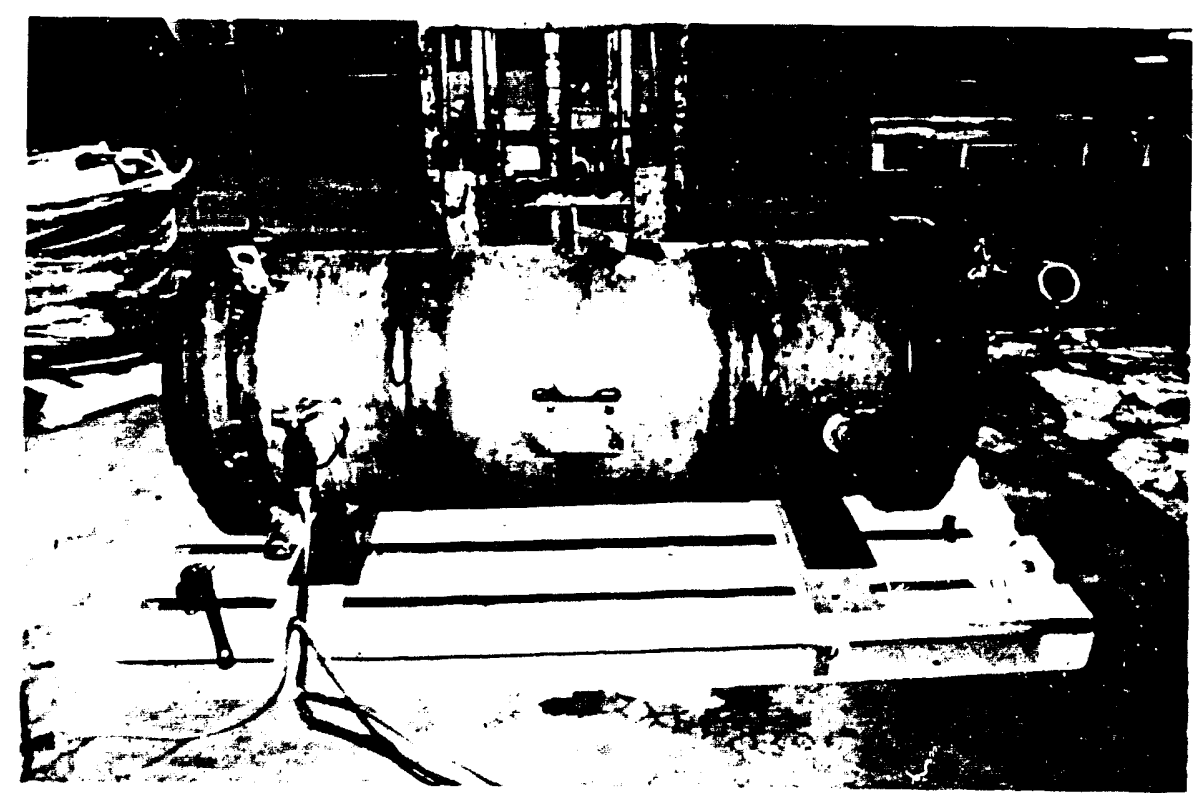

Fig. 23. Chill-storage reactor prior to insulation. 
used to provide ammonia vapor to the reactor. The cylinders were placed in the water trough, and the water heated to $\approx 43^{\circ} \mathrm{C}$ to provide energy and adequate heat transfer for ammonia evaporation. A globe valve in the ammonia vapor line was used to control pressure at the reactor. Instrumentation was installed to provide ammonia vapor mass flow measurement, reactor pressure measurement, water flow rate through the reactor, and temperature of water entering and leaving the reactor. The weight of ammonia bottles was also measured before and after the ammoniation. The type and estimated accuracy of instrumentation is summarized in Table 3. A flow and instrument diagram of the test apparatus is illustrated in Fig. 24.

The first ammoniation proceeded for approximately 2 hours, and $80.2 \mathrm{~kg}$ (176.9 pounds) of ammonia were adsorbed, as determined from initial and final weights of the ammonia bottles. This quantity of ammonia corresponds to 7.7 moles of ammonia per mole of salt, which is the expected saturation level. Cooling water flow during the first ammoniation was $\approx 2.5 \mathrm{\ell} / \mathrm{s}$ ( $40 \mathrm{gal} . / \mathrm{min}$.). Temperature rise through the reactor approached $28^{\circ} \mathrm{C}$, indicating peak rates near 40 moles ammonia per mole of salt per hour, with peak heat generation of nearly $292 \mathrm{~kW}(1$ million Btu/h)

Table 3. Summary specifications of instrumentation used in sorber testing.

\begin{tabular}{|c|c|c|c|}
\hline \# & Measurement & Instrument & Estimated Accuracy \\
\hline F1 & $\begin{array}{l}\text { Ammonia mass } \\
\text { flow }\end{array}$ & $\begin{array}{l}\text { Micromotion } \\
\text { D-100 }\end{array}$ & $\pm 0.3 \mathrm{lb} / \mathrm{min}$ \\
\hline F2 & Water flow & $\begin{array}{l}\text { Orifice meter } \\
\& \text { water } \\
\text { manometer }\end{array}$ & $\pm 0.5 \mathrm{gpm}$ \\
\hline$P$ & $\begin{array}{l}\text { Ammonia pressure } \\
\text { at reactor }\end{array}$ & Setra 208E & $\pm 0.3 \mathrm{psi}$ \\
\hline $\begin{array}{l}\mathrm{T} 1 \& \\
\mathrm{~T} 2\end{array}$ & Temperature & $\begin{array}{l}\text { HYCAL RTD \& } \\
\text { bridge, } \\
0-300^{\circ} \mathrm{C}\end{array}$ & $\pm 0.1^{\circ} \mathrm{C}$ \\
\hline
\end{tabular}




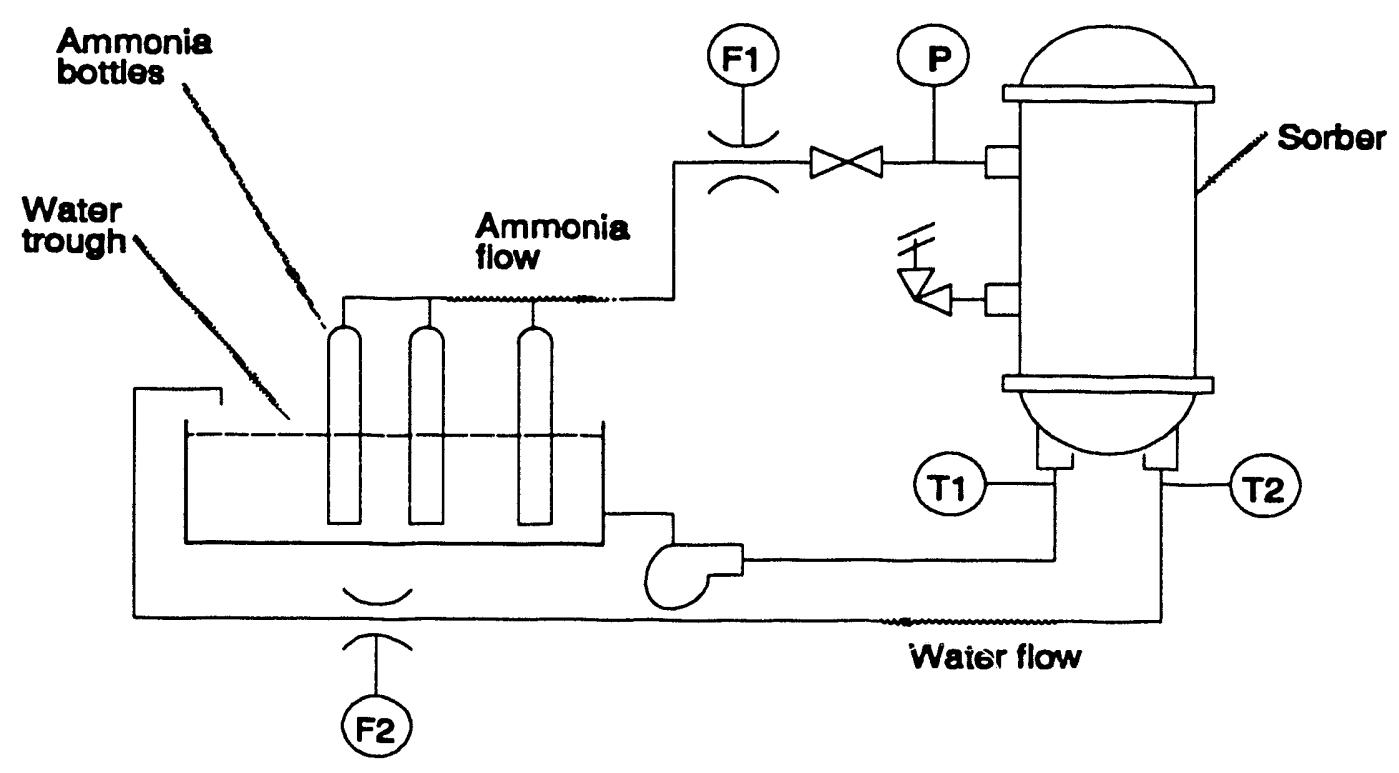

Fig. 24. Test setup for adsorption tests.

Subsequent adsorption testing to determine ammonia uptake rates and capacity were performed with the reactor at $16^{\circ} \mathrm{C}$ nominal temperature, and ammonia vapor at a pressure of $0.95 \mathrm{bar}$, corresponding to an evaporator pressure of $-34^{\circ} \mathrm{C}$. Adsorption was performed in a manner similar to the first adsorption.

Results from the adsorption are plotted in Figs. 25, 26, and 27. Figure 25 is a time trace of temperature of the water into and exiting the sorber during the first few minutes of the sorption. Flow of water through the reactor was $2.5 \mathrm{l} / \mathrm{s}$ (40 gal./min.); a temperature rise of $1^{\circ} \mathrm{C}$ of the water as it flows through the reactor corresponds to a sorption rate of 1.5 moles of ammonia per mole of salt per hour. The significant temperature rise measurea indicated a peak rate of about $10 \mathrm{~mol} / \mathrm{mol}-\mathrm{h}$. However, the inlet temperature was not maintained at the initial value because the temperature of the water bath was increasing due to heat input from the sorption process. The increasing inlet temperature caused the temperature of the entire sorber to increase, and reaction rates 


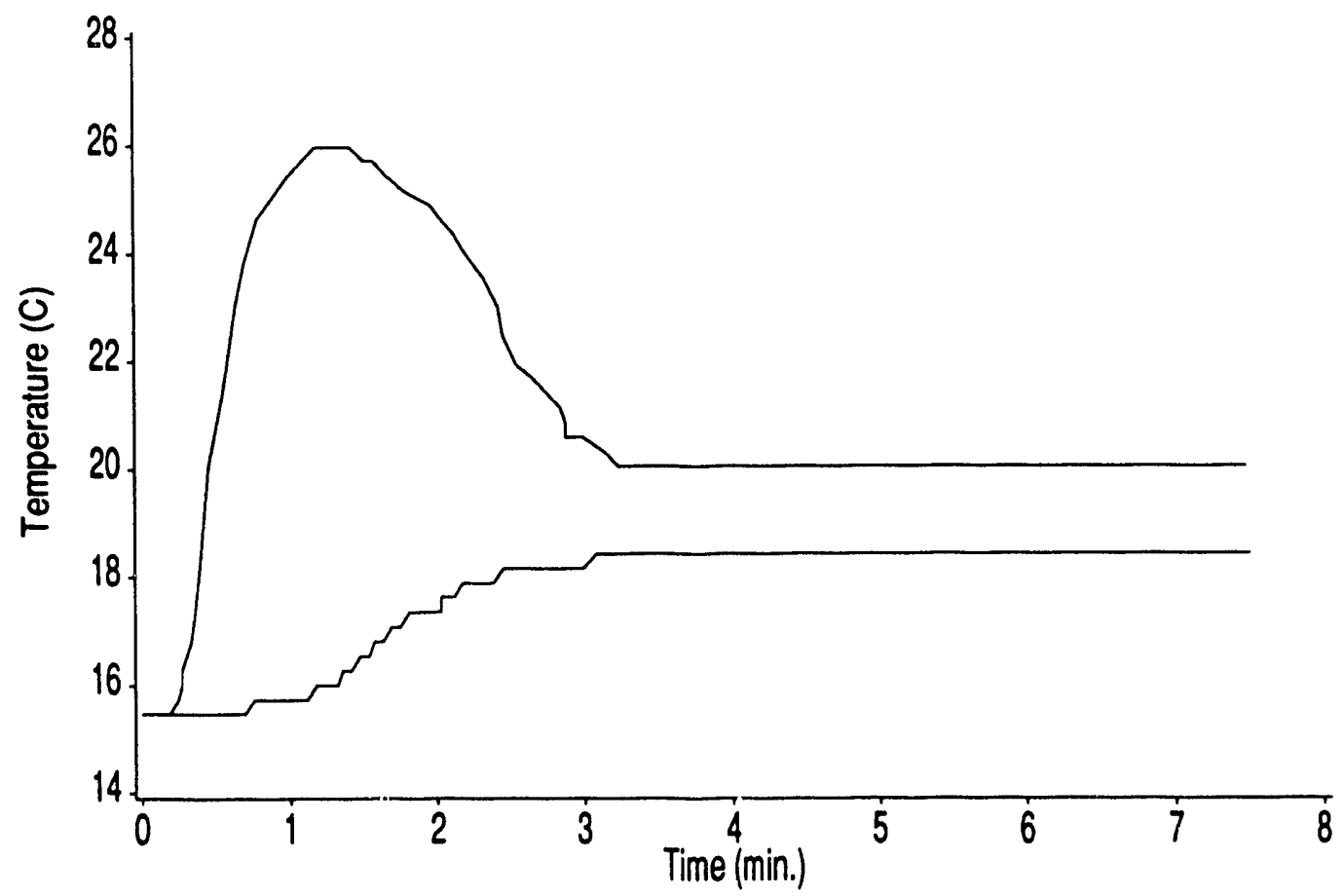

Fig. 25. Inlet and outlet temperatures of cooling water during second adsorption. Cooling water flow is 40 GPM.

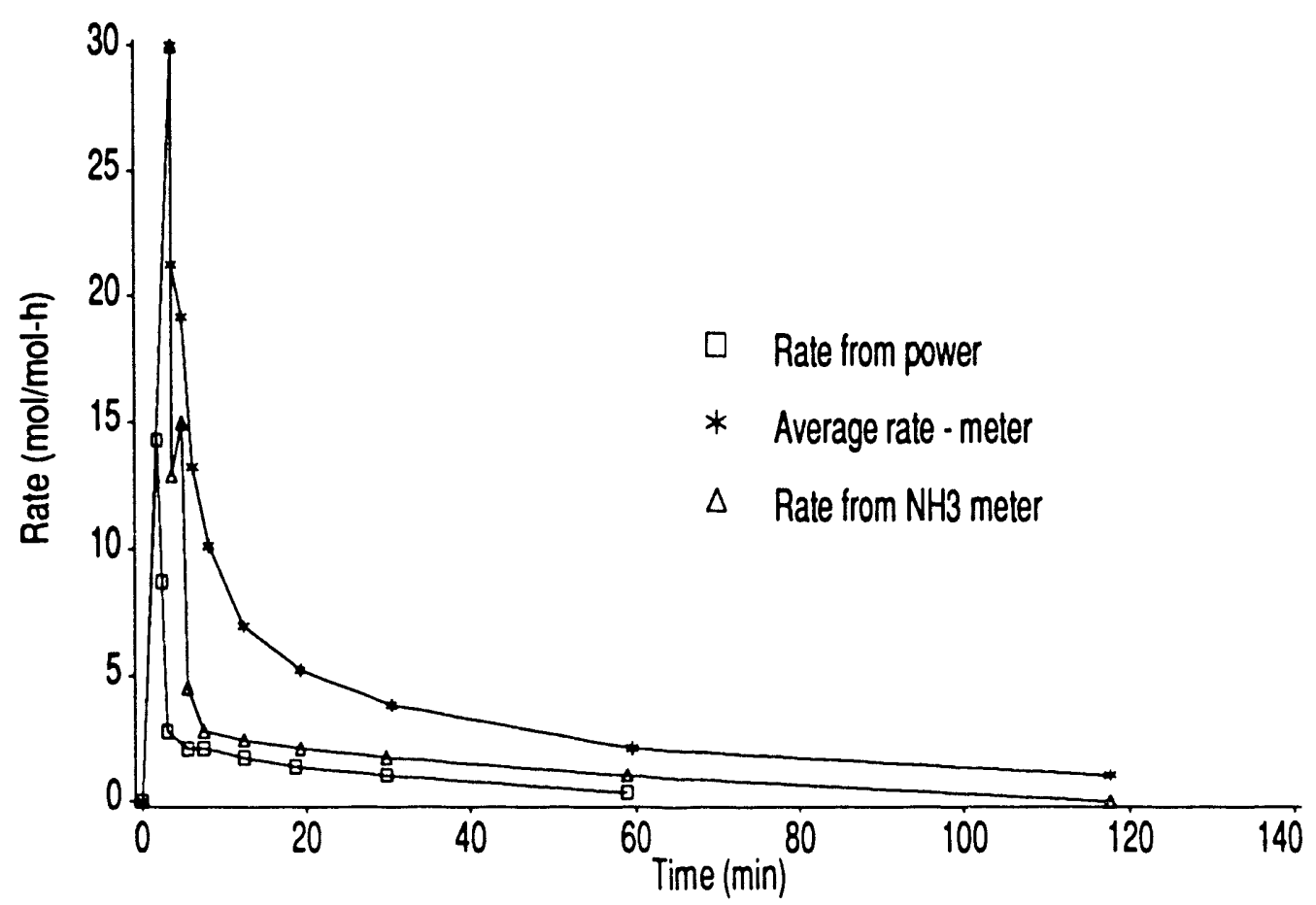

Fig. 26. Reaction rates during the first adsorption at chill storage conditions. 


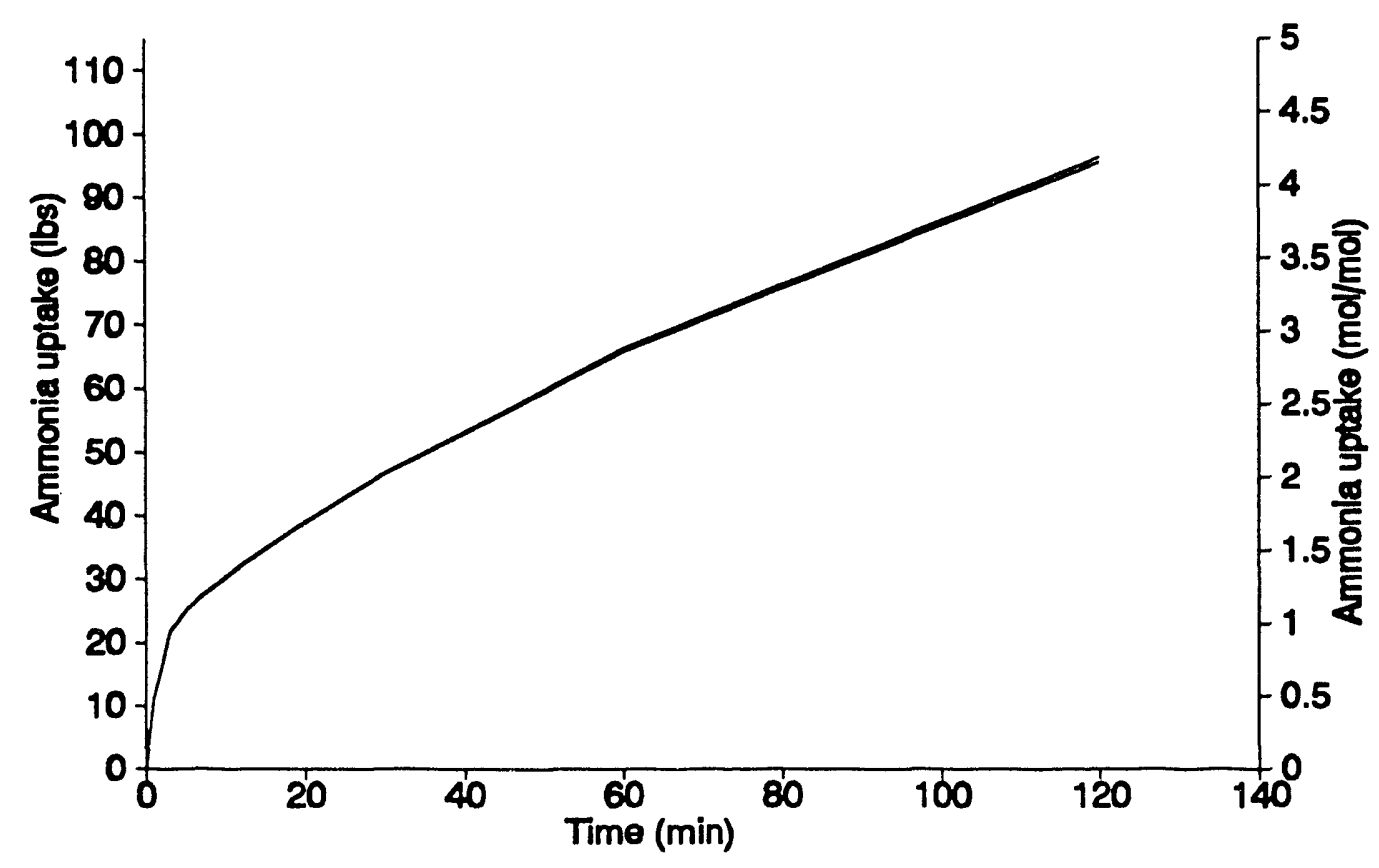

Fig. 27. Ammonia uptake during first adsorption at chill-storage conditions.

derived from power measurements were offset by the power required to heat the reactor. Reaction rates indicated from powe: are therefore below actual rates.

Reaction rates are plotted in Fig. 26. Shown are rates determined from the mass flow meter and rates determined from heat input to the cooling water. Also plotted is the average (defined as the cumulative reaction divided by the elapsed time) reaction rate as determined from the ammonia mass flow meter. Rates measured by the mass flow meter and the power input were found to agree well except during the first few minutes. Response time of the calorimetric measurement were expected to be slow because the temperature of the entire sorber mass was changing. The average sorption rate was found to be over $2 \mathrm{~mol} / \mathrm{mol}-\mathrm{h}$ for the entire sorption. Chill storage systems typically have a discharge window of at least 4 hours; complete discharge in 4 hours requires adsorption rates less than $1.5 \mathrm{~mol} / \mathrm{mol}-\mathrm{h}$. Therefore, the measured average rate of $2 \mathrm{~mol} / \mathrm{mon}$-h was well within the acceptable range. 
Ammonia uptake is plotted in Fig. 27. During the two-hour sorption, nerrly 100 pounds of ammonia were adsorbed, corresponding to adsorption of 4.2 moles of ammonia per mole of salt, which is $60 \%$ of the theoretical coordination sphere. Earlier laboratory tests, in some cases, had achieved somewhat greater uptake rates, with maximum uptake being about $5.5 \mathrm{~mol} / \mathrm{mol}$. However, several sorption cycles were required in the laboratory to achieve optimum uptake and 4.2 was typical for a second adsorption. Utilities (heating and cooling water) used during these tests and project funding were not adequate for cycling, so determination of performance after several cycles could not be made. However, $60 \%$ of theoretical uptake, and $75 \%$ of maximum realistic uptake are very promising results for a first adsorption test at chill storage conditions of the first factory-build sorber.

For normal operation, chill storage charging is performed with a compressor, and the complex compound is desorbed at the pressure of the compressor suction. Testing at these conditions requires either a compressor or an ammonia condenser operating below $-29^{\circ} \mathrm{C}$. As such utilities were not available, desorptions were performed by heating the complex compound to approximately $82^{\circ} \mathrm{C}$ and desorbing to an ammonia disposal system. Problems were encountered with ammonia disposal and testing was interrupted twice, so the desorption did not proceed continuously. The pressure against which the system was desorbed ranged from 3.2 to 1.6 bar. Water temperature leaving the reactor declined from $84^{\circ} \mathrm{C}$ to a minimum of $\approx 67^{\circ} \mathrm{C}$ during the early part of the desorption, and stabilized near $73^{\circ} \mathrm{C}$ for most of the test. Water inlet and outlet temperature recordings made during the desorption are shown in Fig 28. This plot shows temperatures up to 8.5 minutes, at which time the test was interrupted to rectify ammonia disposal problems.

Approach temperatures (deviation from equilibrium, i.e equilibrium temperature at measured pressure less actual temperature) steadily increased during the desorption and are shown in Fig 29. Minimum approach was about $5^{\circ} \mathrm{C}$, and maximum approach was $27^{\circ} \mathrm{C}$. The desorption was stopped at 8.5 and 24.5 minutes and, at these times, the approach temperature decreased due to pressure recovery in the reactor. The approach temperatures for desorption (charging) of chill storage systems depend on compressor suction pressure and condenser temperature, but are typically 5 to $8^{\circ} \mathrm{C}$. Results from this desorption, although not directly applicable to chill storage performance, nevertheless do 


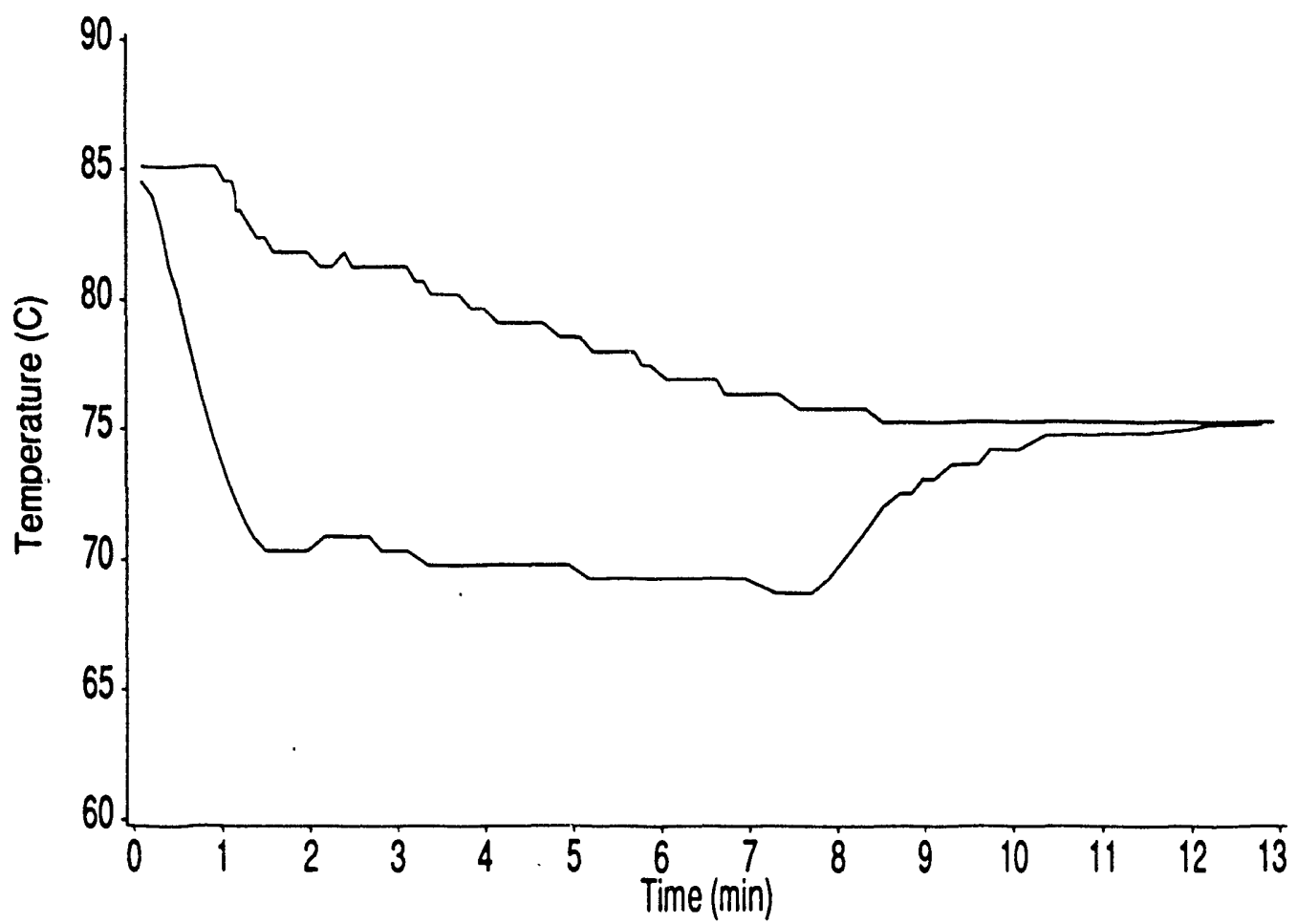

Fig. 28. Inlet and outlet temperatures of water during the first desorption.

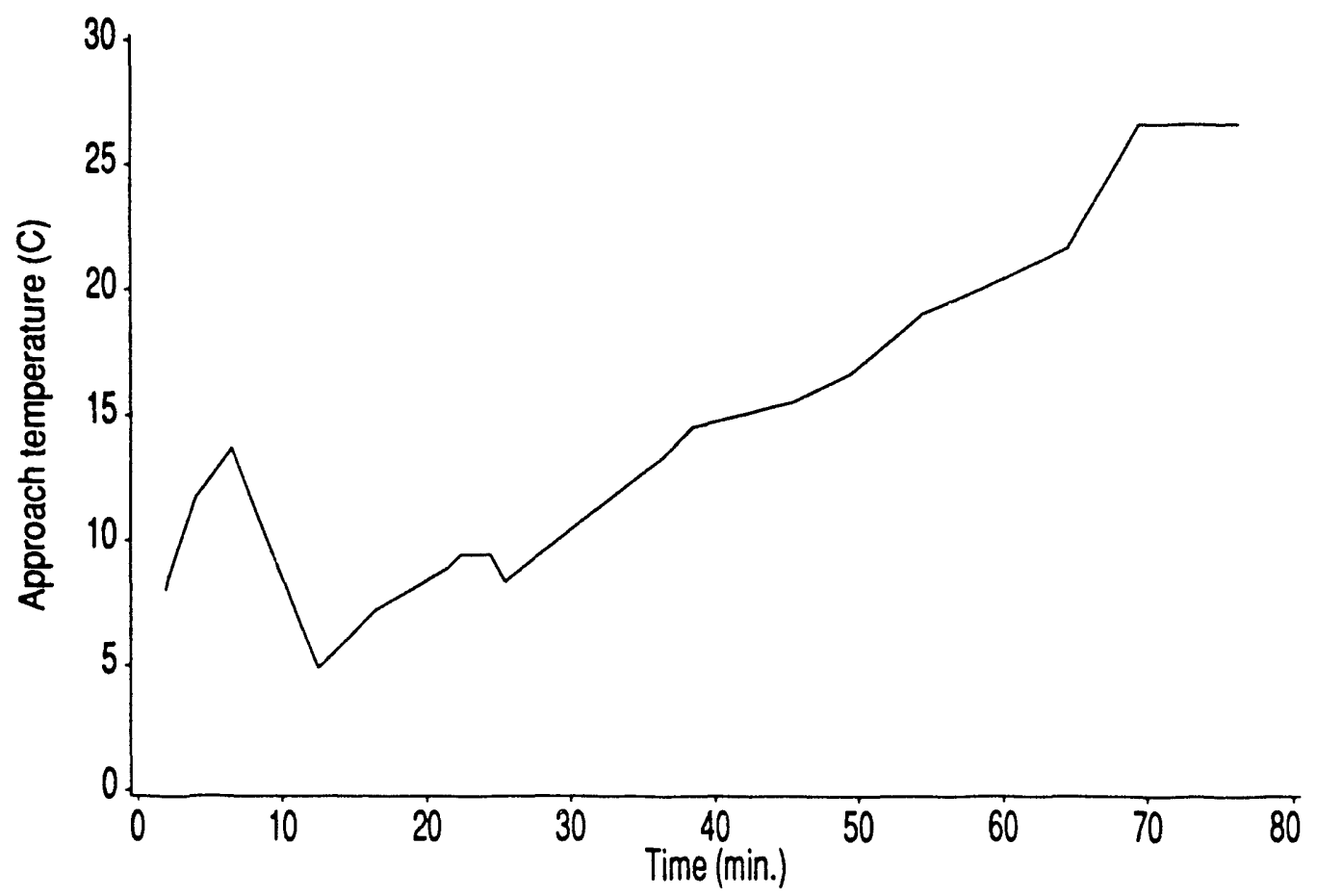

Fig. 29. Approach temperature during desorption. 
indicate that the test reactor can be desorbed, and, as discussed below, performance similar to laboratory performance at comparable conditions was found.

Ammonia mass flow rates during the desorption were made but corrections were required to achieve realistic results. The ammonia mass flow meter indicated a final integrated flow of ammonia vapor $80.6 \mathrm{~kg}$ (177.8 pounds), which is more than the total ammonia added to the system during the first adsorption. At the conclusion of the desorption, the flow meter had an offset of $0.15 \mathrm{~kg} / \mathrm{min}$. $(0.33 \mathrm{lb} / \mathrm{min}$.). If it is assumed that this offset was present during the entire test, the corrected flow would be $69.2 \mathrm{~kg}$ (152.5 pounds). After subtracting $2.1 \mathrm{~kg}$ (4.7 pounds) of ammonia initially contained in the vapor space, this gave a mole number decrease of 6.45. Assuming initial saturation at 7.7 moles, a final mole number of 1.25 is reasonable. Most of the desorption was performed at rates where the meter accuracy was worse than $\pm 5 \%$, so the actual ammonia desorbed was in the range of 6.1 to 6.8 moles. Unlike the adsorption, no final weight measurement was possible, so a check on flow meter calibration could not be made. Desorption rates based on corrected mass flow measurements are plotted in Fig. 30, both as instantaneous and average (again equal to the cumulative reaction divided by the elapsed time) values. Also shown are rates determined from power measurements until the first shutdown at 8.5 minutes. Rates were quite high, with an average rate at the end of the test of over

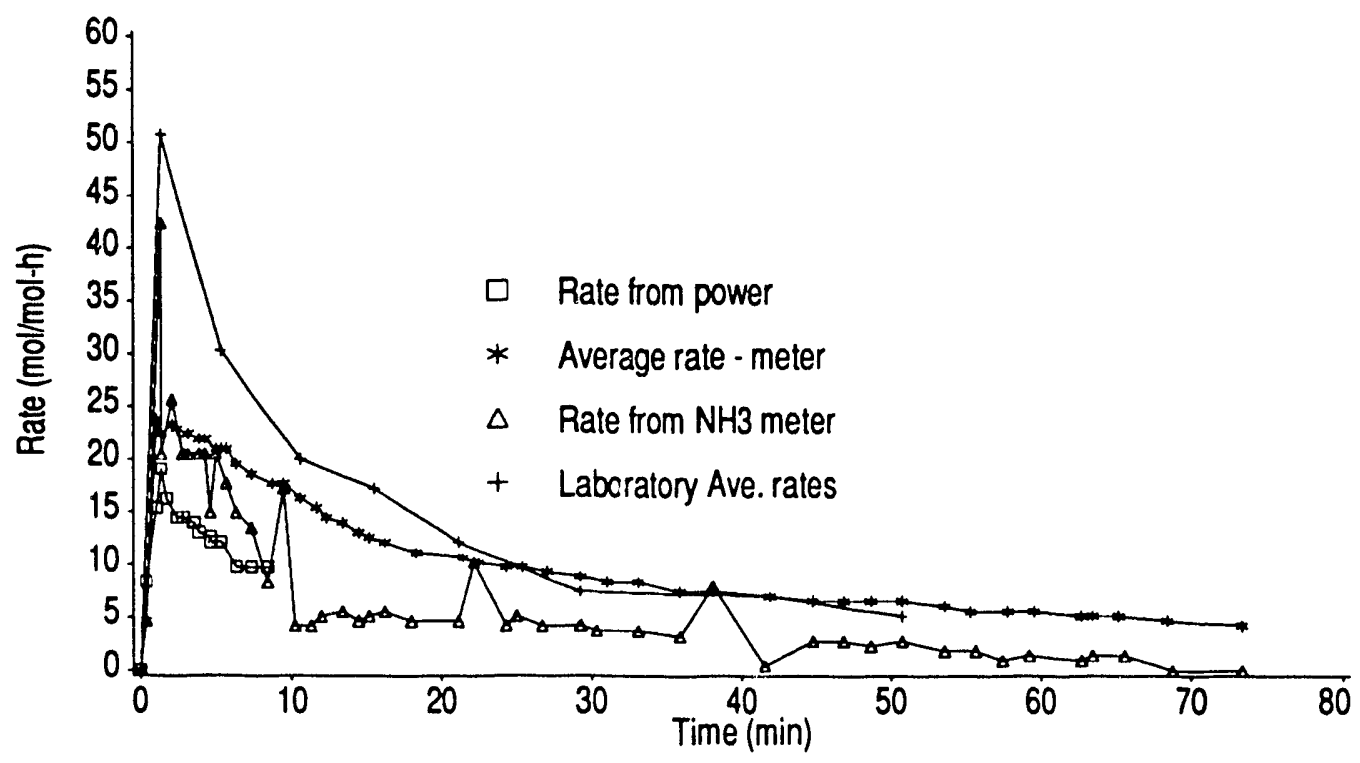

Fig. 30. Reaction rates during the first desorption. 
$5 \mathrm{~mol} / \mathrm{mol}-\mathrm{h}$. This is much higher than needed for chill storage charging, but the approach temperature was also higher than available for chill storage applications. This desorption was compared to earlier laboratory tests at similar conditions. Plotted in Fig. 30 are the average desorption rates from laboratory tests at $85^{\circ} \mathrm{C}$ with $24^{\circ} \mathrm{C}$ approach temperature. Given that (1) desorption of the large-scale reactor was interrupted twice, (2) the water temperature was not maintained constant during the entire desorption, and (3) the initial approach temperatures were much less than that of the laboratory test, the agreement between laboratory and large-scale results is remarkable. The large-scale desorption performed at least as well as laboratory desuiptions. 


\section{ECONOMICS}

Experimental results provided the basis for a realistic cost estimate for a $-24^{\circ} \mathrm{C}$ to $-28^{\circ} \mathrm{C}$ thermal storage system. Based on a 1000 ton-h capacity system and a conservative assumption of a mole number change of 5.0, costs were:

- $\quad$ Adsorbent mass CC180-1580

$21.7 \mathrm{~kg} / \mathrm{ton}-\mathrm{h}$ at $\$ 2.65 / \mathrm{kg}(\$ 1.20 / \mathrm{lb}) \quad=\$ 57.60 /$ ton- $\mathrm{h}$

- Heat exchange surface

$\$ 3.31 / \mathrm{kg}(\$ 1.50 / \mathrm{lb})$ adsorbent $\quad=\$ 72.00 /$ ton- $\mathrm{h}$

- Adsorbent loading and additional reactor internals

$\$ 1.10 / \mathrm{kg}(\$ 0.50 / \mathrm{lb})$ adsorbent $\quad=\$ 24.00 /$ ton $-\mathrm{h}$

- Vessels and enclosures

$\$ 2.20 / \mathrm{kg}(\$ 1.00 / \mathrm{b})$ adsorbent $\quad=\$ 48.00 /$ ton-h.

The above costs were based on vendor quotes for technical grade salts, heat exchange surface, and ASME pressure vessels. This led to a total of approximately $\$ 200 /$ ton-h component cost. Installation and packaging costs were ascertained from manufacturers and application engineers. ${ }^{4.5}$ For a simple system integration, as envisioned for the thermal storage system, a mark up factor of 1.5 to 1.65 is assumed. This led to an estimated installed cost of $\$ 300$ to $\$ 330 /$ ton-h.

The return on investment is largely dependent on electric utility rates. The extremely low consumption of additional electric power during the charge process is one of the major advantages of complex compound thermal storage systems. In utility areas with purchase incentives, returns on investment exceeding $50 \%$ can be achieved. Where no purchase incentives exist, returns are lower but typically not below 30\%. Extensive economic analyses have been performed by Kohlenberger Associates. ${ }^{6}$ The study shows that systems with much higher electrical parasitic penalties than the complex compound system save about $\$ 100 / y r$ and ton-h in utility expenses. Utility cash incentives are typically restricted to $\$ 100,000$. Applying these numbers leads to the above mentioned return on investment of $30 \%$ in areas with no buying incentives, and 45 to $50 \%$ in areas with active buying incentive programs. 


\section{CONCLUSIONS}

Ammoniated complex compounds are attractive media for thermal storage at low temperatures. Research and development has led to reactor hardware with promising operational features, simple integration possibilities into existing refrigeration plants, and attractive projected cost. The development efforts thus far have produced a factoryassembled reactor with a 4 ton-h chill storage capacity.

Test results for the factory-assembled reactor were comparable to those for the laboratory models for both chill storage charge and discharge, although chill storage conditions were not simulated for the charge cycle. These results support the conclusions that chill storage sorbers can be scaled to 4 ton-h or larger, and that factory-assembled sorbers perform as well as laboratory sorbers. Verification of optimum adsorption and desorption-moving more than 5 moles of ammonia per mole of salt-will require several adsorption-desorption cycles, and an ammonia test loop to allow simulation of actual field conditions.

The next phase of complex compound chill storage development should focus on identification, performance verification, and dimensional optimization of the most costeffective type of sorber heat exchanger surface. This will require determination of the actual manufacturing costs of several types of heat exchangers, as well as laboratory performance tests. As a final phase, scale-up, cycleability, and field operation of the optimum heat exchanger surface identified above should be demonstrated. 


\section{REFERENCES}

1. C. Kohlenberger, private communication, Kohlenberger Associates Consulting Engineers, Inc., Fullerton, CA, October 1988.

2. U. Rockenfeller, Development of Dual Temperature Ammines for Heat Pump Latent Heat Storage Application, Final Report, ORNL/Sub/84-47999/1, Oak Ridge National Laboratory, Oak Ridge, Tennessee, March, 1986.

3. U. Rockenfeller, Development of Ammonia-Sodium Bromide Heat Pump/Dual Temperature Storage Concept, Final Report, ORNL/Sub/84-47999/2, Oak Ridge National Laboratory, Oak Ridge, Tennessee, October, 1986.

4. R. Stamm, private communication, Industrial Refrigeration, Inc., Chicago, IL, October 1988.

5. R. Vig, private communication, Vilter Manufacturing Corporation, Milwaukee, WI, July 1988.

6. Kohlenberger Associates Consulting Engineers, Inc., An Investigation into Low-Temperature Thermal Energy Storage Technologies, Fullerton, CA, September 1987. 


\section{APPENDIX: BACKGROUND OF COMPLEX COMPOUND CHEMISTRY}

\section{A.1 COMPLEX COMPOUND EQUILIBRIA}

Complex compounds usually consist of a metal cation which is surrounded jy one or more ions or molecules, generally referred to as ligands. The complex compounds considered here use metal inorganic salts as the cation and ammonia refrigerant as the ligand. These complexes are held together by covalent bonds between the ligand and the adsorbent salt. Ammines and hydrates are the most common representatives of inorganic complex compounds.

The coordination number of a complex compound is defined as the total number of ligand molecules or ions bound to a central molecule or ion. The central particle of a complex compound bonds more particles (ligand molecules) than expected from its charge or from the number of electrons in its outermost shell. This is because the coordinating central adsorbent molecule does not necessarily have an unbalanced charge. Many complex formations are obtained by mere electron displacement as is the case with diammine zinc chloride.

The dissociation energy of a complex compound depends largely on the ligand. For heat pump and thermal storage applications, it is important to achieve a high energy density per unit mass of ligand. Ligands with one lone pair of electrons usually have lower bond energies than those with two lone pairs. For energetic density per unit mass, however, the number of lone pairs must be related to the mole mass of the ligand. Therefore, the ratio of the number of lone pairs to the mole mass of the ligand is a useful measure for the energy density of the bond energies regardless of the central molecule. Applying the above ratio rule leads to ammonia $\left(\mathrm{NH}_{3}\right)$ and water $\left(\mathrm{H}_{2} \mathrm{O}\right)$ as the most promising ligands. ${ }^{1}$

For solid-vapor metal inorganic complex compounds such as hydrates and ammines, the ligand vapor pressure is a function of temperature. However, within one coordination polyhedron, the vapor pressure is independent of the molar ratio of adsorbent 
to adsorbate (salt to refrigerant). Barium chloride, for example, can adsorb up to eight moles of ammonia in one conrdination step. The respective phase diagram is shown in Fig. A.1.

$\mathrm{BaCl}_{2} \mathrm{n} \mathrm{NH}_{3} \leftrightarrow \mathrm{BaCl}_{2}+\mathrm{n} \mathrm{NH}_{3}$ with $0 \leq \mathrm{n} \leq 8$

The equilibrium constant for this reaction can be expressed with the activities (a) of ine setants and products.

$K_{e q}=\frac{\left[a_{(\mathrm{BaCl})}\right]^{1 / 8}\left[a_{(\mathrm{NH} 3)}\right]}{\left[7_{\mathrm{BaCl}} \cdot 8 \mathrm{NH} 3\right]^{1 / 8}}$

The activity is a function that correlates changes in the chemical potential associated with changes in quantities such as concentrations or partial pressures. For one-step mechanisms,

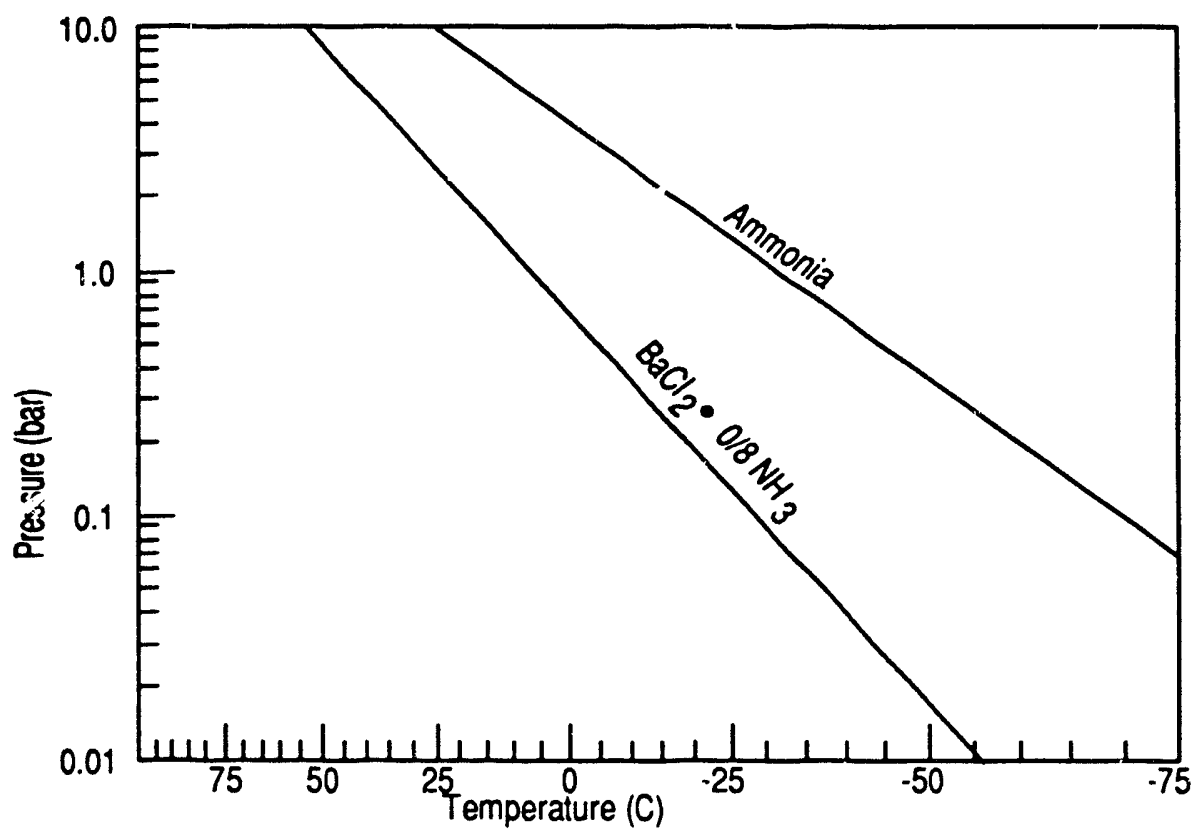

Fig. A.1. Phàse diagtamin fór $\mathrm{BaCl}_{2}=\mathrm{O} / \mathrm{ONNI}_{3}$. 
the equilibrium constant can be expressed with the reaction constants of the forward and reverse reaction.

$K_{e q}=\frac{k_{f}}{k_{b}}$

Equation (A.2) is known as the law of mass action. Gas activities are often approximated by concentrations or partial pressures and the activities of solids are taken to be unity.

$\mathrm{K}_{\mathrm{p}}=\frac{\left[\mathrm{a}_{(\mathrm{BaCl2})}\right]^{1 / 8}\left[\mathrm{a}_{(\mathrm{NH} 3)}\right]}{\left[\mathrm{a}_{(\mathrm{BaC12} \cdot 8 \mathrm{NH3})}\right]^{1 / 8}} \approx \frac{[1]^{1 / 8} \mathrm{p}_{(\mathrm{NH} 3)}}{1} \approx \mathrm{p}_{(\mathrm{NH} 3)}$

The activities of salts and ammoniates in liquid solutions depend on the molar ratio of adsorbent to absorbate and are therefore not constant. Hence, those activity constants cannot be taken to be unity. Even for solid coordinative adsorbents and complexes, this can only be considered an approximation because the change in chemical potential with ligand concentration, due to the shielding effect and interaction of the ligand molecules, is omitted in this consideration.

The maximum amount of energy released in an isobaric and isothermal process that is free to produce useful work is Gibbs free energy (G), defined as

$\mathrm{G}=\mathrm{H}-\mathrm{TS}$.

In the equilibrium state, both reactants and products possess the same free energy; therefore, $\Delta \mathrm{G}=0$. However, because of irreversibilities of real processes, work obtained from spontaneous processes is always less than predicted by $\Delta G$. For constant $T$ and $p$, change in Gibbs function during a process can be written as

$\Delta \mathrm{G}=\Delta \mathrm{H}-\mathrm{T} \Delta \mathrm{S}$

Although $\Delta \mathrm{G}$ may predict if a process is spontaneous, no information on reaction rates can be derived. The criterion for a chemical equilibrium in ideal gas phases can be expressed as 
$\ln K_{p}=-\frac{\Delta G^{\circ}}{R_{m} T}$

where $\Delta G^{\circ}$ is the standard free energy of the reaction. Equations (A.6) and (A.7) lead to

$\ln K_{p}=\frac{\Delta S^{\circ}}{R_{m}}-\frac{\Delta H^{\circ}}{R_{m} T}$.

With Eq. (A.4), the relationship of the equilibrium pressure to the absolute temperature is

$\ln p($ lig $)=\frac{\Delta S^{\circ}}{R_{m}}-\frac{\Delta H^{\circ}}{R_{m} T}$

where $\Delta S^{\circ}$ and $\Delta H^{\circ}$ are the standard entropy and enthalpy changes of the reaction and $R_{m}$ is the universal gas constant.

Analyses of complex compounds in the 1930s and 1940s were based mainly on the New Heat Theorem from Nernst. The Nernst approximation formula,

$\log p(\operatorname{lig})=\frac{\mathrm{Q}_{0}}{2.303 \mathrm{R}_{\mathrm{m}} \mathrm{T}}+1.75 \log \mathrm{T}-\mathrm{aT}+\mathrm{C}$,

is a first approach to predict the vapor pressure of a complex by means of heat evolution and vice versa. ${ }^{2} Q_{0}$ represents heat evolution in Joules, $R_{m}$ is the universal gas constant, " $\mathrm{a}$ " is a constant for the coordination step, and C is a constant for the ligand.

For many complex compounds, the "a" value has been approximated with a formula developed by Biltz and Huettig. For ammoniated complex compounds this formula is a linear correlation between the value of " $a$ " and the coordination number. ${ }^{3}$

This useful approximation proved to be a simple tool to predict the heat evolution with an accuracy of approximately $\pm 7 \%$. However, the equations are only valid for pressures well below the critical pressure of the ligand because they are based on ideal gas law assumptions. 


\section{A.2 HEAT AND MASS TRANSFER IN COMPLEX COMPOUNDS}

Sorption rates in porous sorbents are controlled mostly by sorbate transport within the pore network rather than by kinetics of surface sorption. Bulk flow through the pores is generally negligible such that the intraparticle transport must be considered a diffusive process. Such processes are described by Fick's first equation, which correlates the sorbate flux $\mathrm{J}$ with the diffusivity $\mathrm{D}(\mathrm{c})$ and the concentration gradient:

$J=-D(c) \frac{\partial c}{\partial x}$.

Pore diffusion may occur via several mechanisms depending on the pore size, the sorbate concentration, and other conditions. ${ }^{4.5}$

Transport in intracrystalline pores usually is referred to as micropore diffusion. Molecules diffusing in micropores never escape the adsorbent's surface force; transport requires an activated process involving jumps between sorbent sites.

Diffusion in larger pores, such that the diffusing molecule escapes from the surface field, is referred to as macropore diffusion. Since actual reactions always use an assemblage of microparticles rather than one single isolated particle, the additional diffusional resistance associated with sorbate transport through the crystal bed must also be considered in a micropore diffusion analysis. This particular macropore diffusivity is often referred to as bed diffusivity.

In an adsorbate layer or pellet assumed to have isothermal behavior, the sorption rate may be controlled by micropore diffusion, macropore diffusion, or a combination thereof. If the micropore resistance is dominant, the concentration gradient must appear in the microparticle rather than in the layer or pellet, and the layer thickness or gross particle size should have only a minor influence on the sorption rate. If macropore resistance is the rate limiting mechanism, the concentration with the microparticle must be uniform and the adsorption rate depends on the layer thickness or gross particle size. 
Experiments performed with several different salts as the adsorbent and ammonia as the adsorbate revealed a strong dependence of the adsorption rate on the layer thickness; this leads to the conclusion that for this case, macropore diffusion is the rate limiting diffusion mechanism.

\section{REFERENCES}

1. U. Rockenfeller, Development of Dual Temperature Ammines for Heat Pump Latent Storage Application - Final Report, ORNL/Sub/84-47999/1, March 1986, available from National Technical Information Service, Springfield, VA.

2. W. Nernst, The New Heat Theorem, New York: Dover Publications, 1969.

3. W. Biltz and G. Huettig, "Ueber Ammoniakverbindungen der Halogenide," Zeitschrift f. anorg. Chemie., 109, S. 89, 1919.

4. F. A. L. Dullien, Porous Media, Fluid Transport, and Pore Structure, New York: Academic Press, 1979, Chap III.

5. M.D. Ruthven, "Zeolites as Selective Adsorbents," Chemical Engineering Progress, February 1988, pp.42-50. 
ORNL/Sub/86-57432/1

Dist. Category UC-202

\section{Internal Distribution}

1. M. R. Ally

2. T. D. Anderson

3. S. H. Buechler

4. R. S. Carlsmith

5. W. G. Craddick

6. J. B. Drake

7. D. M. Eissenberg

8. P. D. Fairchild

9. W. Fulkerson

10. J. E. Jones Jr.

11 L. Jung

12. M. A. Kuliasha

13. W. R. Mixon

14. M. Olszewski
15. A. E. Ruggles

16. A. C. Schaffhauser

17. M. Siman-Tov

18. T. K. Stovall

19. M. J. Taylor

20-24. J. J. Tomlinson

25. C. D. West

26. A. Zucker

27. ORNL Patent Section

28. Central Research Library

29. Document Reference Section

30-31. Laboratory Records Department

32. Laboratory Records (RC)

\section{External Distribution}

33. Robert E. Cates, Director, Advanced Engineering, Baltimore Aircoil Company, Inc., P.O. Box 7322, Baltimore, MD 21227

34. Kevin Drost, Battelle Pacific Northwest Laboratories, P. O. Box 999, Battelle Blvd., Richland, WA 99352

35. Russ Eaton, Advanced Utility Concepts Division, U.S. Department of Energy, Forrestal Bldg., CE-142, 1000 Independence Ave., Washington, DC 20585

36. Ted Gillis, Corporate Director, Lennox Industries, Box 809000 , Dallas, TX 75380-9000

37. D. E. Gound, Program Manager, Research Management Branch, Department of Energy, ORO, P.O. Box 2001, Oak Ridge, TN 37831-8611

38. Dr. Philomena Grodzka, 526 Cleermont Drive, SE, Huntsville, AL 35801

39. Terry Jones, Marketing Manager, North Star Ice Equipment Corporation, Box 70668, Seattle, WA 98107

40. William E. Kahlert, Evapco, Inc., 3120 Frederick Ave., Baltimore, MD 21229

41. Landis Kannberg, Battelle Pacific Northwest Laboratories, P.O. Box 999, Battelle Blvd., Richland, WA 99352 
42. Don Kemp, Senior Application Engineer, Turbo Refrigerating Company, 1815 Shady Oaks Drive, P.O. Box 396, Denton, TX 76202

43. Kurt W. Klunder, Director, Office of Energy Management, Office of Utility Technology, U.S. Department of Energy, CE-14, Forrestal Bldg., 1000 Independence Ave., Washington, DC 20585

44. David E. Knebel, P.E., General Manager Thermal Products, Paul Mueller Co., P.O. Box 828, Springfield, MO 65801

45. Dr. Richard J. Kooy, P.E., Design Engineer, Chicago Bridge \& Iron Technical Services Company, Research Center, 1501 North Division Street, Plainfield, IL 80544-8929

46. George Lane, Dow Chemical Company, 1776 Building, Midland, MI 48640

47. David R. Laybourn, Reaction Thermal System, 840 Latour Ct., Suite A, Napa, CA 94558

48. Kevin Longe, Executive Officer, IMECO, 3820 Highway 26, Polo, Il 61064

49. Dr. V. Lottner, Kernforschungsanlage Jlich GmbH, PLE, Postfach 1913, D-5170 Jlich, Germany

50. Calvin D. MacCracken, Calmac Manufacturing Corporation, P.O. Box 710, Englewood, NJ 07631

51. George Manthey, Department of Energy, ORO, P.O. Box 2001, Oak Ridge, TN 37831

52. Tony Padilla - H2H, Manager, New Technology, Florida Power Corporation, 3201 - 34th Street South, Box 14042, St. Petersburg, FL 33733

53. Robert Pokelwaldt, President, Frick Co., 345 W. Main Street, Waynesboro, PA 17268

54. Veronica A. Rabl, Electric Power Research Institute, 3412 Hillview Ave., P.O. Box 10412, Palo Alto, CA 94303

55. Eberhart Reimers, Advanced Utility Concepts Division, U.S. Department of Energy, Forrestal Bldg., CE-142, 1000 Independence Ave., Washington, DC 20585

56-60. Dr. Uwe Rockenfeller, President, Rocky Research, 1598 Foothill Drive, P.O. Box 1086, Boulder City, NV 89005

61. Robert L. San Martin, Deputy Assistant Secretary, Office of Utility Technology, U.S. Department of Energy, Forrestal Bldg., CE-10, 1000 Independence Ave., Washington, DC 20585

62. Dr. Chang Sohn, U.S. Army Construction Engineering Research Laboratory, Corps of Engineers, Box 4005, Champaign, IL 61824-4005

63. Dr. Richard H. Stamm, P.E., President, Industrial Refrigeration, Inc., 1414 South Redwood Drive, Mr. Prospect, IL 60056

64. Mr. Robert J. Vig, Director of Marketing, Vilter Manufacturing Corporation, 2217 South First Street, Milwaukee, WI 53207

65. Ronald D. Wendland, Project Manager, Thermal Storage Technology, P.O. Box 10412, 3412 Hillview Ave., Palo Alto, CA 94303 
66. Office of Assistant Manager for Energy Research and Development, Department of Energy, ORO, Oak Ridge, TN 37831

67-76. Given distribution as shown in DOE/OSTI-4500-R75 under category UC-202 (Thermal Energy Storage) 

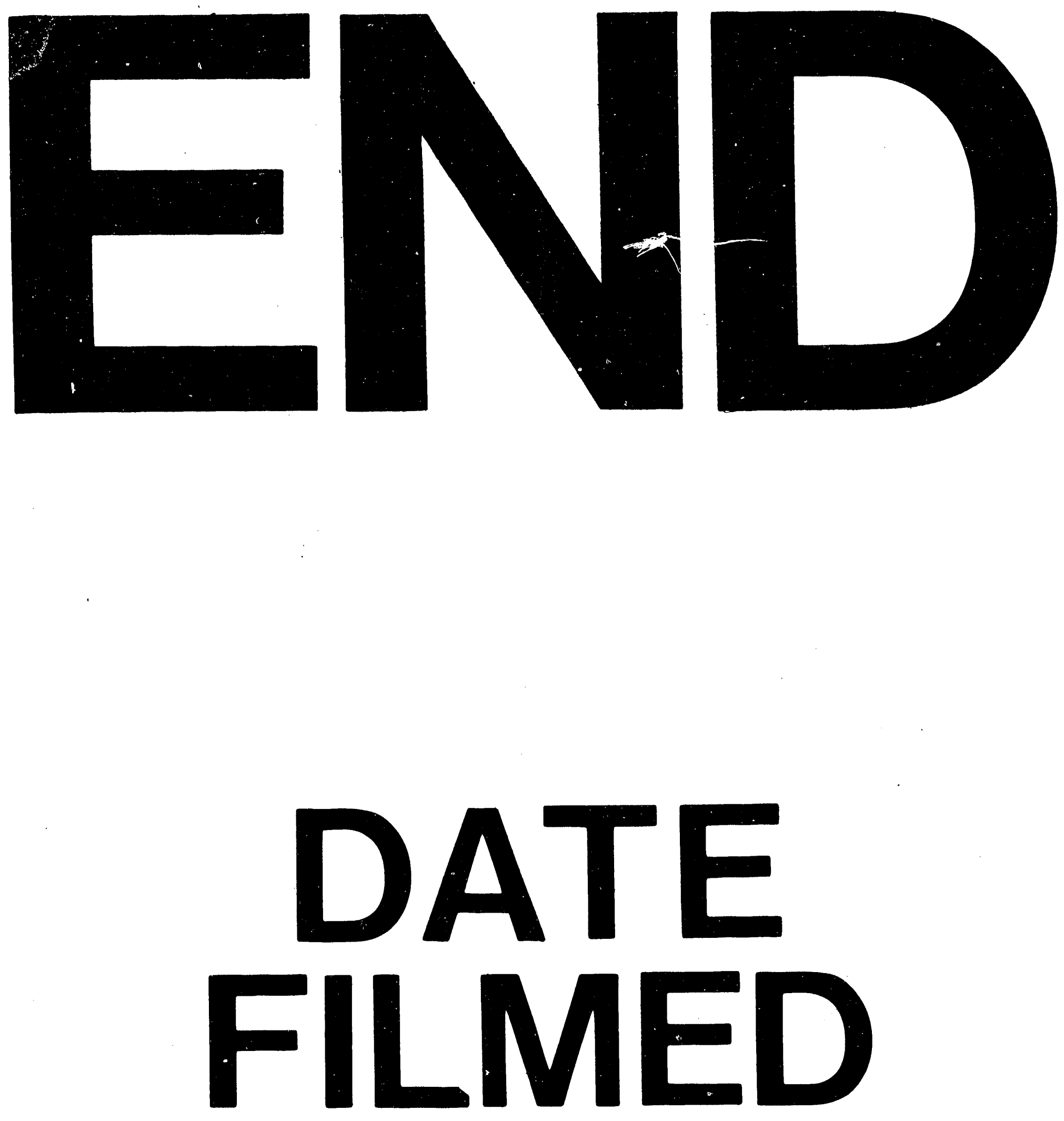

1

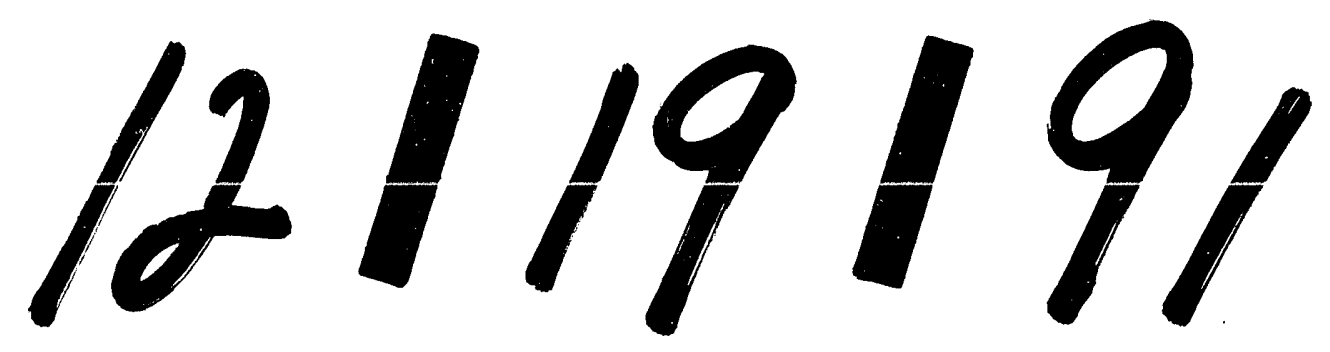


